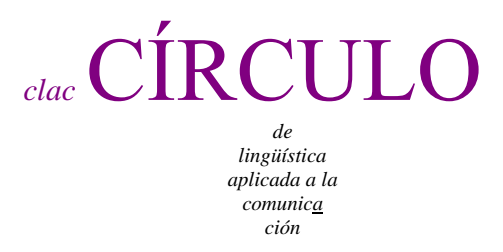

$61 / 2015$

\title{
EL SISTEMA PRONOMINAL ÁTONO EN LA VARIEDAD DE ESPAÑOL EN CONTACTO CON EL MAYA YUCATECO
}

\author{
Edith Hernández, Azucena Palacios \\ Universidad Quintana Roo, Universidad Autónoma de Madrid \\ edith en uqroo $\mathrm{mx}$, azucena palacios en uam es
}

\section{Resumen}

En esta investigación analizamos el sistema pronominal átono (tercera persona) de hablantes de español en contacto con maya yucateco a partir de un corpus compuesto por entrevistas y una tarea lingüística realizadas a 27 participantes, clasificados por su grado de mono/bilingüismo y nivel de instrucción. Mediante un análisis multivariado, se determinaron relaciones de dependencia entre las variables, con cruces entre variables internas y externas.

Mostramos que este sistema evidencia una tendencia similar a la que constatamos en otras variedades de español en situación de contacto lingüístico intenso: las formas pronominales átonas de acusativo tienden a no especificar los rasgos de género y número. Argumentamos que al proceso de gramaticalización de las formas pronominales como concordancias de objeto que se desarrolla desde el español antiguo, se unen las características de la lengua de contacto, el maya, que actúa como un acelerador del

Hernández, Edith, y Azucena Palacios. 2015.

El sistema pronominal átono en la variedad de español en contacto con el maya yucateco.

Círculo de Lingüística Aplicada a la Comunicación 61, 36-78.

http://www.ucm.es/info/circulo/no61/hernandez.pdf

http://revistas.ucm.es/index.php/CLAC

http://dx.doi.org/10.5209/rev_CLAC.2015.v61.48467

(C) 2015 Edith Hernández y Azucena Palacios

CÍRCULO de Lingüística Aplicada a la Comunicación (clac)

Universidad Complutense de Madrid. ISSN 1576-4737. http://www.ucm.es/info/circulo 
cambio y que posibilita la reorganización y recategorización del sistema pronominal átono de tercera persona, prácticamente completada en el grupo de los bilingües consecutivos de español como L2. Y a partir de este grupo el cambio se va expandiendo al resto de los grupos, precisamente en las entidades más prototípicas de objeto (definidas, inanimadas y continuas) en contextos de alta accesibilidad, donde el referente está más activo en la mente del hablante y del oyente.

Palabras clave: español, maya yucateco, pronombres átonos, contacto lingüístico.

\section{Abstract}

In this paper we examine the atonic pronominal system (third person) of Spanish speakers in contact with Yucatec Maya. The corpus included interviews and a language task from 27 participants, who were classified according to their degree of mono/bilinguism and their education level. By means of a multivariate analysis, dependence relations between the variables, with crossings between internal and external ones, were determined.

We demonstrate that this system evidences a tendency similar to the one found in other varieties of Spanish in intense language contact: the atonic pronominal forms of accusative tend not to specify the features of gender and number. We argue that along with the process of grammaticalization of the pronominal forms as object agreement, the Maya language acts as an accelerator of the change and enables the reorganization and recategorization of the atonic pronominal system of third person. This change has been completed in the consecutive bilinguals of Spanish as L2; and from this group, the change is spreading to the others displayed precisely in the most prototypical object entities (defined, inanimate and continuous), and in highly accessible contexts, where the referent is more active in the speaker and the interlocutor's mind.

Key words: Spanish, Yucatec Maya, atonic pronouns, language contact. 
Índice

1. Introducción 38

2. La comunidad de habla 39

3. La hipótesis 42

4. El corpus 43

5. El análisis 44

5.1. Reconstrucción del sistema pronominal átono de la muestra 44

5.2. Análisis de las variables género del referente y mono/bilingüismo 47

5.3. Reconstrucción del sistema pronominal en función del número del referente 50

5.4. Análisis del sistema pronominal en función de la variable "nivel de instrucción" 53

5.5. Análisis del sistema pronominal en función de variables gramaticales y discursivas 55

6. El maya yucateco 65

7. La discusión 67

8. A modo de conclusión 73

Bibliografía 74

\section{Introducción}

En esta investigación ${ }^{1}$ analizamos el sistema pronominal átono de hablantes de español en contacto con maya yucateco y mostramos que este evidencia una tendencia similar a la que constatamos en otras variedades de español en situación de contacto lingüístico intenso: las formas pronominales átonas de acusativo ${ }^{2}$ tienden a no especificar los rasgos de género y número, como se aprecian en los ejemplos siguientes.
a. Tal vez quieran un autógrafo o... saludarlo o... algo así [a un actor].
b. Allá mi difunta mamá lo llevan a hacer... comida allá.
c. Dos banquillos agarro así...lo pongo así. Me paro a moler.
d. Porque esas iglesias que se han construido, lo han... lo han construido los norteamericanos.

\footnotetext{
${ }^{1}$ Esta investigación se ha desarrollado en el marco del proyecto "El español en contacto con otras lenguas: variación y cambio lingüístico", financiado parcialmente por el Ministerio de Economía y Competitividad (Ref. FFI2012-31702). Investigación apoyada también por el CONACYT (México).

${ }^{2}$ Constatamos igualmente una tendencia similar en las formas de dativo, que tienden a no especificar el rasgo de número (Hernández, en prensa).
} 
Consideramos que estas variaciones son parte de un cambio lingüístico en progreso, motivadas tanto por la influencia de la lengua de contacto, el maya, como por la evolución interna del español. Mostramos que se trata de un cambio inducido por contacto sistemático y coherente, cuyo resultado, la simplificación de los rasgos gramaticales que rigen el sistema, es eficiente y está regida por patrones gramaticales distintos a los que rigen el sistema etimológico o el referencial del centro y norte de España. No se trata, en ningún caso, de una simplificación motivada por una adquisición deficiente de la lengua o por un empobrecimiento de la misma, sino de un cambio lingüístico que obedece a otras necesidades comunicativas.

Se trata, pues, de un cambio que se produce a partir de una variación existente previamente en el español, ya que desde el español medieval se documentan cambios en el sistema pronominal átono, un área inestable de la gramática de esta lengua y, por tanto, más expuesta al cambio. En estas situaciones, la lengua de contacto actúa como un acelerador del proceso de variación, produciendo, al menos en el habla oral coloquial, un cambio lingüístico que, como veremos, puede llegar a reorganizar un paradigma completo de la lengua. Las consecuencias lingüísticas de estos cambios inducidos por contacto permiten suponer que ha tenido lugar la convergencia de las estructuras congruentes de las lenguas implicadas en el proceso.

\section{La comunidad de habla}

En la península de Yucatán, en México, el español convive con la lengua maya desde la época colonial en una situación de bilingüismo histórico y cultural. En términos estadísticos, la lengua maya yucateca cuenta con 786,113 hablantes; la segunda lengua indígena con mayor número de hablantes después del náhuatl, según el INEGI (2010). La población se distribuye en los estados de la península de Yucatán del siguiente modo: Yucatán con 537, 618 mayahablantes, Quintana Roo cuenta con 177, 979 y Campeche tiene 71, 852 .

Pfeiler (1999) señala que en la península de Yucatán el uso del español y el maya varía según las regiones económicas; la pesquera, por ejemplo, es la que tiene menos hablantes de maya. En Campeche, el español predomina sobre el maya en el occidente y sur del estado. En Quintana Roo, se observan tres regiones con un diferente uso de 
lenguas: el Caribe, con predominio del español y del inglés; el centro, región lingüística maya más conservadora; y el sur, donde predomina el uso del español. Esta situación, asegura Pfeiler (1999: 269), se debe a "una infraestructura ampliada de las comunidades rurales y (a) una tasa alta de migración relacionada con el turismo y el crecimiento de las ciudades”. Coincide con esto último Sánchez Arroba (2009), quien apunta a la economía deprimente de los pueblos indígenas como causa importante de la migración y de la pérdida de la lengua maya en Quintana Roo.

Chetumal, capital del estado de Quintana Roo, y lugar donde se desarrolló el presente estudio, se localiza en el sur-este de la península y del estado. Al sur, y a unos treinta minutos, tiene de vecino al país de Belice (donde el inglés es la lengua oficial, pero se hablan también el español, el inglés criollo, el chino, y el hindi, entre otras lenguas); al norte, pero centro del estado, se localizan ciudades y pueblos que integran la llamada "zona maya" (donde el maya y el español coexisten principalmente). Más al norte y bordeando el Caribe, se ubican las ciudades turísticas como Tulum, Playa del Carmen y Cancún (donde se escucha español e inglés y, en menor medida, maya y otras lenguas europeas).

En el municipio de Othón P. Blanco -del cual Chetumal es parte- la población mayahablante es de 21, 859, según el INEGI (2010). Las actividades principales en Chetumal son la gestión del gobierno, el comercio y la educación. Estudiantes provenientes de Belice y de otras ciudades y pueblos del estado participan día con día en el mosaico cultural de Chetumal. Inmigrantes de diversos estados del país han hecho de Quintana Roo su nuevo hogar, y Chetumal ha sido uno de esos polos de atracción para muchos inmigrantes. Gente originaria de Yucatán, Ciudad de México, Veracruz, Tabasco y más recientemente de Chiapas, han emigrado a la capital del estado. Por supuesto, inmigrantes del mismo estado también se han integrado a esta ciudad, y entre ellos, muchos mayahablantes. Si bien, como señala Pfeiler (1999), el español predomina en el sur de Quintana Roo, aún en las calles, mercados o en las aulas escolares se observan rasgos de un bilingüismo instrumental (español L1-maya L2 limitado) y, en menor medida, de un bilingüismo consecutivo (maya L1-español L2).

Los estudios de actitudes hacia la lengua maya yucateca en México se han realizado principalmente en el estado de Yucatán (Heijmen 2006; Álvarez Murillo 2008; Sima 
Lozano 2011 y 2012; Sima Lozano, Perales Escudero y Be Ramírez 2014; Pfeiler 1993; Durán Caballero y Sauma Castillo 2003). Sin embargo, son incipientes las investigaciones en Quintana Roo sobre el tema de actitudes hacia el maya (Sánchez Arroba 2009; Canché Teh 2014; Hernández y Sima, en prensa). Con respecto a los primeros, los resultados de los distintos estudios no parecen coincidir. Mientras que algunos (Durán Caballero y Sauma Castillo 2003) reportan actitudes positivas hacia la lengua maya, otros muestran lo contrario (Heijmen 2006, Álvarez Murillo 2008); o una mezcla de actitudes -positivas hacia la lengua, pero negativas hacia los hablantes indígenas-, como es el caso de Sima (2011 y 2012).

Con respecto a las actitudes en Quintana Roo, Sánchez Arroba (2009), a partir de entrevistas en cuatro comunidades mayas en Quintana Roo, ofrece datos cualitativos y cuantitativos que explican la pérdida progresiva de la lengua maya en esta región, propiciada por factores diversos, entre los cuales se observan actitudes negativas y una falta de lealtad por parte de los mayahablantes hacia su lengua.

Canché Teh (2014) realizó un estudio cuyo objetivo fue conocer las razones de la escasa comunicación en lengua maya de los estudiantes en la Universidad Intercultural Maya de Quintana Roo. Para ello, analizó el discurso de profesores y estudiantes. En sus hallazgos destacan la falta de motivación de los alumnos, las actitudes negativas hacia el uso del maya tanto de docentes como de alumnos, y la limitada competencia comunicativa en maya.

En un estudio reciente, Hernández y Sima (en prensa) realizaron una investigación comparando las actitudes hacia el maya, el español y el inglés en tres ciudades: Mérida (Yucatán), Cancún y Chetumal (Quintana Roo). Los autores encontraron que la muestra de la ciudad de Cancún mantiene actitudes más positivas hacia todas las lenguas, seguida de Mérida; la muestra en Chetumal evidenció actitudes positivas hacia el español y más neutras y negativas hacia el inglés y el maya, respectivamente. Así mismo, reportaron que las actitudes de los bilingües (maya-español) fueron en general, en las tres ciudades, más positivas hacia todas las lenguas que las de los monolingües de español.

De lo anteriormente señalado los estudios en Quintana Roo sobre actitudes, la inmigración, las actividades económicas y el contacto entre las lenguas de dichos 
inmigrantes y los originarios se deduce un lento pero progresivo desplazamiento del maya y el predominio del español en Chetumal.

\section{La hipótesis}

La hipótesis que subyace a este trabajo es que los fenómenos de contacto suponen procesos generales de cambio en los que actúan mecanismos similares, que dan lugar a efectos o consecuencias lingüísticas similares también. Mostraremos, en este sentido, que el sistema pronominal átono de los hablantes en nuestro corpus puede explicarse como un cambio indirecto inducido por contacto donde intervienen factores internos y externos. Este cambio se produce en dominios vulnerables o inestables de la gramática (Matras 2007), donde previamente había variación lingüística, documentada ya en el español antiguo.

Consideramos que los hablantes bilingües aprecian congruencia estructural ${ }^{3}$ en ciertos puntos de sus lenguas, en nuestro caso la gramaticalización del género morfológico o su ausencia, y los hacen converger para obtener un mayor rendimiento comunicativo. Eliminan, para ello, la distinción de género como patrón de selección pronominal y reorganizan el sistema en función de esta decisión. De igual manera, tienden a neutralizar los rasgos de número en las formas pronominales, cambio en progreso que se constata en el caso de las formas pronominales de dativo del español. Esto supondría la consolidación de las formas pronominales como concordancias de objeto.

Se trata, pues, de un proceso general de cambio influido por el contacto con el maya que implica la neutralización de los rasgos de género y de número, lo que produce un resultado lingüístico de simplificación ${ }^{4}$ morfológica del paradigma pronominal.

Consideramos, según esto, que los hablantes monolingües de español que no están inmersos en un ambiente bilingüe mostrarán un patrón más cercano al etimológico, que

\footnotetext{
${ }^{3}$ Consideramos que lo que cuenta en los cambios inducidos por contacto en situaciones de contacto intenso no es la congruencia o convergencia tipológica de las lenguas sino las similitudes que los hablantes pueden percibir en ciertas estructuras de las lenguas que dominan, esto es, la congruencia de ciertos rasgos, formas, funciones o relaciones (Palacios y Pfänder 2014, Thomason 2014).

4 Entendemos "simplificación" de rasgos gramaticales, no de la gramática, ya que los hablantes deben crear nuevas estrategias para establecer la referencia de los clíticos, evaluar su accesibilidad y explotar posibles usos pragmáticos de los mismos en función de esa evaluación (anticipación del objeto en el verbo, mayor afectación del objeto, etc.).
} 
es el normativo, a diferencia de los hablantes bilingües, que mostrarán un sistema que tiende hacia la simplificación de rasgos morfológicos, esto es, un cambio en proceso aún no consolidado totalmente. Esperamos, pues, encontrar una gradación entre el sistema etimológico y el sistema simplificado en función de la variable bilingüismo/monolingüismo. Dado que el sistema etimológico es el normativo, presente en los medios de educación, las instituciones educativas, culturales, etc., creemos que el nivel de instrucción puede ser también una variable que condicione la selección de las formas pronominales.

Consideramos, en definitiva, que esta simplificación morfológica de las formas pronominales de acusativo supone un proceso de gramaticalización en el que los pronombres derivan a concordancias de objeto; proceso aún no acabado, gradual, donde el grupo de los monolingües de español mostraría el menor número de formas emergentes y el de los bilingües consecutivos con español como L2 tendría una variación mayor con respecto a las formas canónicas.

\section{El corpus}

El corpus se elaboró a partir de entrevistas semidirigidas y una tarea lingüística en la que los informantes tenían que describir situaciones a partir de unas imágenes, que incluía referentes animados e inanimados, femeninos y masculinos, singulares y plurales. En algunos casos, la investigadora hacía preguntas adicionales con respecto a la imagen para elicitar el uso de pronombres de objeto directo. Los informantes fueron siete hombres y veinte mujeres, que se clasificaron por su grado de mono/bilingüismo en cuatro grupos: 6 monolingües de español (GI); 8 bilingües instrumentales, con poco dominio de la lengua maya (GII); 3 bilingües simétricos, con dominio de ambas lenguas (GIII) y 10 bilingües consecutivos con dominio de maya (GIV).

Por nivel de instrucción, se integraron dos grupos: 15 de educación básica; y 12 de instrucción media y superior. La edad de los informantes fue de 17 a 60 años; 25 de los 27 tenían contacto con la lengua maya, ya sea por medio de uno de los padres o de los abuelos.

El corpus se integró de 499 casos de pronombres átonos de tercera persona y pronombre nulo de objeto directo. Se eliminaron casos ambiguos en los que el referente no era 
claro; casos de expresiones o frases lexicalizadas y aquellos de se impersonal seguido de pronombre átono, dado que en México es habitual se le/les y no hay evidencia de variación.

Para el análisis de los datos se usaron siete variantes de la variable lingüística (pronombre de objeto directo): la, lo, las, los, las, le, les y Ø. Como variables internas independientes se consideraron el género, el número, la animacidad, la definitud, la especificidad, la continuidad del referente, así como la accesibilidad del referente; se tomó en cuenta igualmente la animacidad del sujeto.

Mediante un análisis multivariado, se analizaron los datos para determinar relaciones de dependencia de las variables, con cruces entre variables internas y externas. También se determinó la significancia de la dependencia de variables por medio de $\chi^{2}$, la $\mathrm{V}$ de Cramer y el coeficiente de contingencia.

El estudio se inició con un análisis de todas las variantes lingüísticas (la, lo, las, los, las, le, les y Ø); después se recodificaron en grupos para examinar los rasgos de género y número. También inicialmente se analizaron las variables externas: bilingüismo e instrucción considerando los diferentes grupos; posteriormente, se recodificaron estas variables integrando grupos. Se realizaron pruebas de $\chi^{2}$ considerando todas las variables internas y externas y se seleccionaron las que resultaron significativas en relación de dependencia. Los resultados se presentan en tablas de contingencia con porcentajes, frecuencias y los valores de $\chi^{2}$, la V de Cramer y el coeficiente de contingencia.

\section{El análisis}

\subsection{Reconstrucción del sistema pronominal átono de la muestra}

En esta sección analizamos los datos del corpus para comprobar si nuestra hipótesis sobre la reorganización del sistema pronominal átono de tercera persona en el español hablado en la zona (la neutralización de los patrones de género y número en las formas pronominales de objeto directo) es válida, y, en caso de que así sea, si la influencia de la lengua maya ha tenido algún papel en esta reorganización. 
Para poder constatar si existe tal reorganización del sistema pronominal átono de tercera persona, analizamos las apariciones de las formas pronominales de objeto directo $(\mathrm{la} / \mathrm{s}$, lo/s y le/s) así como los objetos nulos ${ }^{5}$, lo que nos permitirá reconstruir el sistema pronominal átono de tercera persona de los hablantes de la muestra. Nuestra hipótesis de partida es que en esta zona de contacto lingüístico se está produciendo la reorganización del sistema pronominal átono hacia un sistema basado en el caso pero con neutralización de los rasgos de género y de número en las formas pronominales, esto es, los pronombres de objeto se convierten en formas de concordancia de objeto. Esto supondría que el sistema pronominal no solo se ha reorganizado sino que se ha recategorizado.

Para corroborar o refutar nuestra hipótesis, realizamos el recuento de las formas pronominales de objeto directo documentadas en el corpus distribuidas en función del género y del número del referente. Procedimos a analizar, en primer lugar, el estudio de la variable género del referente; posteriormente, abordamos la variable número del referente. Así, con el objeto de averiguar si el género del referente es significativo en la elección de las formas, agrupamos bajo un mismo ítem el singular y plural de cada forma pronominal.
a. Está el gatito... pero no la dejan comer.
b. Pos nosotros lo lavamos el nixtamal.
c. Entró el tigre y lo jaló la... niña y lo llevó en el monte.
d. Quizás perdió los libros; los dejó en casa; no los llevó a la escuela.
e. Sólo yo trabajo para atender ellos.
f. Pues aquí estaban jugando futbol los dos niños. Llegó la mamá y le está regañando porque rompieron un jarrón.
g. Es una... grabadora.... que lo ... que se lo está vendiendo o le están grabando o le están entrevistando [una ancianita].
h. Le estaba sacudiendo para que no le duela [el pie].
i. ¿Recuerdas cómo se jugaba la kimbomba? Sí, sí recuerdo.

Los resultados se muestran en la tabla 1.

\footnotetext{
${ }^{5}$ Hernández (en prensa) analiza la pronominalización del objeto indirecto en esta zona y concluye que se hace mayoritariamente con la forma $l e(s)$, el $94.5 \%$ de los casos.
} 


\begin{tabular}{|l|l|l|l|l|}
\hline \multicolumn{5}{|c|}{ Tabla 1. Reconstrucción sistema pronominal con variable género } \\
\hline & La/s & Lo/s & Le/s & $\emptyset$ \\
\hline Masculino & $2 / 327$ & $276 / 327$ & $26 / 327$ & $23 / 327$ \\
& $0.61 \%$ & $84.4 \%$ & $7.95 \%$ & $7 \%$ \\
\hline Femenino & $47 / 132$ & $70 / 132$ & $7 / 132$ & $8 / 132$ \\
& $35.6 \%$ & $53 \%$ & $5.3 \%$ & $6 \%$ \\
\hline Proposición & $2 / 40$ & $32 / 40$ & $2 / 40$ & $4 / 40$ \\
& $5 \%$ & $80 \%$ & $5 \%$ & $10 \%$ \\
\hline $\mathrm{N}=499$ & \multicolumn{4}{|l|}{} \\
\hline
\end{tabular}

(Pearson $\chi^{2} 128.03$ p $>0.000$, Coeficiente de contingencia: 0.452 , V de Cramer 0.358)

Dado que lo que interesa es comprobar si la variable género del referente condiciona la elección de las formas, nuestra atención se centrará en la formas pronominales con referentes femeninos, puesto que es en estos casos donde aparece una mayor variación ${ }^{6}$. Como anunciamos en $\S 4$, hemos procedido a hacer un análisis bivariado para corroborar si las variables estudiadas están asociadas $\left(\chi^{2}\right)$ y el grado de asociación que muestran (coeficiente de contingencia y V de Cramer). En efecto, es significativo comprobar que las variables "formas pronominales" y "género del referente" están asociadas (0.000) con un grado de asociación moderado-bajo (0.452 y 0.358).

Si hacemos un análisis detallado de los resultados, comprobamos que las formas lo(s) alcanzan el 53\% de los usos pronominales con referentes femeninos, una tasa superior a la de las formas canónicas $l a(s)$, con el $35.6 \%$ de las apariciones totales. Estos datos constatan, de manera contundente, que en el sistema pronominal átono de tercera persona de esta zona existe una variación considerable en las formas pronominales que remiten a objetos femeninos, lo que puede ser indicio de que se está produciendo un cambio en progreso, esto es, la reorganización del sistema pronominal basado en patrones exclusivamente de caso, sin diferenciación del género de las formas. Si esto es así, podemos suponer que se estaría corrigiendo la asimetría que el sistema pronominal átono del español tiene entre las formas de dativo, sin diferenciación de género, y las de acusativo, originalmente con diferenciación de género.

Las formas pronominales le(s) con referente femenino son muy poco significativas, el $5.3 \%$, con un porcentaje similar a los casos de leísmo con referentes proposicionales, el

\footnotetext{
${ }^{6}$ En trabajos posteriores se abordará el análisis de los casos de leísmo y de elisión de objeto.
} 
5\%, e inferior al de los casos de leísmo con referentes masculinos, el 7.95\%. Estas cifras suponen que la variable género no es significativa en los casos de leísmo, a diferencia de lo que ocurre con las formas $l o(s)$. En cuanto a los objetos nulos, los porcentajes correspondientes a referentes masculinos, el 7\%, a referentes femeninos, el 6\%, y a referentes proposicionales, el $10 \%$, son relativamente similares, lo que indica igualmente que la variable género tampoco es significativa en relación con los objetos nulos.

En resumen, estos resultados constatan que, en efecto, existe una tendencia hacia la neutralización de la distinción de género en las formas de acusativo, un cambio en progreso que debemos analizar con mayor detalle.

\subsection{Análisis de las variables género del referente y mono/bilingüismo}

Si nuestra hipótesis de partida es que en esta zona de contacto lingüístico intenso se está produciendo un cambio en el sistema pronominal átono, en consonancia con los documentados en otras zonas de contacto lingüístico, y que el contacto con la lengua maya es el motor que impulsa el cambio, se espera: a) que los bilingües tengan un mayor número de apariciones de formas pronominales $l o(s)$ con referentes femeninos que los monolingües; b) que los bilingües con predominio de la lengua maya aumenten considerablemente los usos de estas formas con referentes femeninos.

Para corroborar nuestras hipótesis, es preciso analizar las formas pronominales documentadas en función del tipo de hablantes, esto es, monolingües (GI) y bilingües, y estos últimos en bilingües según el grado de dominio de las dos lenguas de contacto: bilingües instrumentales con poco dominio de la lengua maya (GII), bilingües simétricos con dominio de ambas lenguas (GIII) y bilingües consecutivos con dominio de maya (GIV).

(3) a. Quizás perdió los libros; los dejó en casa; no los llevó a la escuela. (GI).

b. Por ejemplo, en... la masa, ya la amasamos, le pusimos manteca y todo. O sea, lo, lo colamos. (GII).

c. Pero, pues yo no, no sabía cómo se decía el nombre de esos bichitos; yo los conocí en maya ¿no? (GIII).

d. Ya lo llevaron la niña. Quién sabe dónde lo llevaron. (GIV). 
Los resultados se muestran en la tabla $2^{7}$ :

\begin{tabular}{|c|c|c|c|c|c|c|c|}
\hline & & $\mathrm{La} / \mathrm{s}$ & & $\mathrm{Lo} / \mathrm{s}$ & $\mathrm{Le} / \mathrm{s}$ & $\varnothing$ & \\
\hline \multirow{3}{*}{$\begin{array}{l}\text { GI. } \\
\text { Monolingües } \\
\text { español }\end{array}$} & Mascul. & $0 / 83$ & $0 \%$ & $70 / 83 \quad 84.3 \%$ & $9.6 \%$ & $5 / 83$ & $6 \%$ \\
\hline & Femen. & $15 / 30$ & $50 \%$ & $20 \%$ & $6.7 \%$ & $4 / 30$ & $13.3 \%$ \\
\hline & Propos. & $0 / 6$ & $0 \%$ & $46 / \quad 66.7 \%$ & $16.7 \%$ & $1 / 6$ & $16.7 \%$ \\
\hline \multirow{3}{*}{$\begin{array}{l}\text { GII } \\
\text { Instrumental } \\
\text { Maya L2 }\end{array}$} & Mascul. & $0 / 94$ & $\overline{0 \%}$ & $\begin{array}{lll}75 / 94 & 79.8 \%\end{array}$ & $14 / 94 \quad 14.9 \%$ & $\overline{5 / 94}$ & $\begin{array}{l}5.3 \% \\
\end{array}$ \\
\hline & Femen. & $19 / 32$ & $59.4 \%$ & $37.5 \%$ & $3.1 \%$ & $0 / 32$ & $0 \%$ \\
\hline & Propos. & $0 / 9$ & $0 \%$ & $88.9 \%$ & $0 \%$ & $1 / 9$ & $11.1 \%$ \\
\hline \multirow{3}{*}{$\begin{array}{l}\text { GIII. } \\
\text { Simétricos }\end{array}$} & Mascul. & $0 / 40$ & $0 \%$ & $32 / 40$ & $3 / 40$ & $5 / 40$ & $12.5 \%$ \\
\hline & Femen. & $9 / 19$ & $47.4 \%$ & $47.4 \%$ & $0 \%$ & $1 / 19$ & $5.3 \%$ \\
\hline & Propos. & $0 / 7$ & $0 \%$ & $71.4 \%$ & $14.3 \%$ & $1 / 7$ & $14.3 \%$ \\
\hline \multirow{3}{*}{$\begin{array}{l}\text { GIV. } \\
\text { Consecutivos } \\
\text { Español L2 }\end{array}$} & Mascul. & $2 / 110$ & $1.8 \%$ & 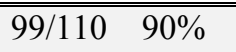 & $1 / 110$ & $8 / 110$ & $7.3 \%$ \\
\hline & Femen. & $4 / 51$ & $7.8 \%$ & $84.3 \%$ & $1 / 51$ & $3 / 51$ & $5.9 \%$ \\
\hline & Propos. & $2 / 18$ & $11.1 \%$ & $83.3 \%$ & $0 / 18$ & $1 / 18$ & $5.6 \%$ \\
\hline
\end{tabular}

(GI: Pearson Chi-Square 61.03 p $>0.000$, Coeficiente de contingencia: 0.582, V de Cramer 0.506), (GII: Pearson Chi-Square 74.22 p>0.000, Coeficiente de contingencia: 0.596, V de Cramer 0.524), (GIII: Pearson Chi-Square $27.04 \mathrm{p}>0.000$, Coeficiente de contingencia: 0.539, V de Cramer 0.453), (GIV: las variables no están asociadas).

En esta tabla se han analizado las variantes "género del referente" y "formas pronominales" en función de los cuatro grupos sociales establecidos. Como se aprecia, hay grado de asociación de las variables en todos los grupos excepto en el de los bilingües consecutivos, lo que significa que estos hablantes no seleccionan sus formas pronominales en función del género del referente, ya que la forma no marcada, y por tanto más extendida, es $l o(s)$, independientemente de si remite a una entidad masculina, femenina o neutra. Esto es, en este grupo se ha producido la reorganización del sistema pronominal. En los otros grupos, observamos que el grado de asociación de las variables es moderado, como indican el coeficiente de contingencia y la V. de Cramer.

Así, vemos que en el grupo de los monolingües de español, para los que se esperaría un sistema pronominal átono etimológico similar al de otras áreas mexicanas, las formas pronominales $l o(s)$ para referentes masculinos son mayoritarias, el $80 \%$, con un pequeño porcentaje de leísmo masculino, el 7.5\%, y un $12.5 \%$ de objetos nulos; cifras estas que estimamos similares a las de otras zonas mexicanas. Sorprende, sin embargo, comprobar que exista mayor variación en las formas pronominales con referentes

\footnotetext{
${ }^{7}$ Para reconstruir el sistema pronominal átono de todos los grupos se analizaron todas las formas pronominales de acusativo del corpus, 499, incluyendo elisiones y formas cuyo antecedente era una oración anterior.
} 
femeninos: el 50\% de los referentes femeninos corresponde a la forma $l a(s)$, el $20 \%$ a la forma lo(s) mientras que el $16.7 \%$ son casos de leísmo. Encontramos, en definitiva, que casi el 50\% de los usos pronominales con referente femenino no se expresa a través de la forma pronominal que aporta los rasgos de género, $l a(s)$, sino que los hablantes seleccionan formas pronominales prototípicas para masculino, $l o(s)$, o formas de dativo que no admiten la distinción de género, le(s).

El grupo que tiene el español como lengua primera y el maya como lengua segunda con adquisición incipiente muestra un comportamiento similar al del grupo de los monolingües en el uso de las formas pronominales con referente masculino, pero la distribución de las formas con referentes femeninos se concentra en las formas canónicas $l a(s)$, el 59.4\%, y en las formas en emergencia lo(s) con el $37.5 \%$, ya que los casos de leísmo femenino son poco significativos, el 3.1\%. Nótese la polarización de las formas con referentes femeninos documentada en este grupo.

El grupo de los bilingües simétricos de español y maya muestra resultados ciertamente interesantes: las formas pronominales para referentes masculinos alcanzan tasas similares a las de los grupos anteriores; por el contrario, las formas pronominales con referentes femeninos consolidan la polarización de las formas, avistada en el grupo anterior, con el mismo porcentaje de apariciones de $l a(s)$ y de $l o(s)$, el $47.4 \%$.

Finalmente, el grupo de los bilingües consecutivos con predominio de la lengua maya, arroja frecuencias relativas de uso que muestran que el cambio, la neutralización de la variable género en la selección de las formas, está muy avanzado, ya que el $84.3 \%$ de las entidades con referente femenino se pronominaliza con $l o(s)$; el $7.8 \%$ de los casos corresponde a los usos canónicos de la(s) y apenas aparecen casos de leísmo, el 2\%. En cuanto a los objetos nulos, se perciben tasas similares a las de los otros grupos, el 5.9\%.

Lo que estos datos evidencian, en definitiva, es que está teniendo lugar un cambio en progreso a favor de la forma no marcada $l o(s)$. Por otra parte, la variable bilingüismo es un factor altamente significativo que está directamente relacionado con la extensión del cambio.

Es interesante ver, igualmente, que los porcentajes de leísmo con referente femenino disminuyen en función del papel más activo de la lengua maya; así, el grupo de los 
monolingües presenta las tasas más altas de leísmo, el 16.7\%, y el de los consecutivos no llega al $2 \%$.

A la vista de los resultados anteriores, se hacía necesario comprobar la extensión de la variación en estudio en todos los grupos, la aparición de las formas emergentes sin especificación de género, por lo que procedimos a realizar un análisis que midiera las frecuencias relativas de uso de las formas pronominales que remiten a entidades masculinas o femeninas descartando los casos de elisiones y de formas pronominales cuyo antecedente es una oración o proposición anterior; medimos igualmente el grado de asociación de las variables analizadas: formas emergentes $l o / s$ con referentes femeninos y grupos mono/bilingües. Los resultados se muestran en la tabla 3. Nótese la gradación de menor a mayor tasa de aparición de esta forma en función del grado de bilingüismo de los hablantes, del $23.1 \%$ al $89.6 \%$, lo que nos permite obtener una perspectiva del cambio en progreso que está teniendo lugar. El grado de asociación de las variables es moderado (0.485 y 0.555$)$.

\begin{tabular}{|l|ll|ll|ll|ll|}
\hline \multicolumn{7}{|l|}{ Tabla 3. Lo(s) con referentes femeninos y variable monolingüismo/bilingüismo } \\
\hline & GI Monolingües & \multicolumn{2}{|c|}{ GII Bil. Instrum. } & G III Bil. Simét. & GIV Bil. Consec. \\
\hline $\begin{array}{l}\text { Lo/s } \\
{[+ \text { femenino }]}\end{array}$ & $6 / 26$ & $23.1 \%$ & $12 / 36$ & $37.5 \%$ & $9 / 9$ & $50 \%$ & $43 / 48$ & $89.6 \%$ \\
\hline $\mathrm{N}=124$ (sin proposiciones ni elisiones) \\
\hline
\end{tabular}

(Pearson Chi-Square 38.193. $\mathrm{p}>0.000$, Coeficiente de contingencia 0.485, V de Cramer 0.555).

\subsection{Reconstrucción del sistema pronominal en función del número del referente}

Hemos constatado la existencia de un cambio en progreso en el sistema pronominal de los distintos grupos en relación con el género del referente; por ello, pasemos a continuación a analizar los usos pronominales de la muestra en función del número del referente para comprobar si tiene lugar un cambio similar, esto es, si existen formas pronominales singulares con referente plural y en qué proporción aparecen.
a. Pues si está vendiendo mi mamá en el parque, pues la voy a acompañar.
b. Empezaba a agarrar piedras y las tiraba a las casas de los otros vecinos.
c. Mi esposo lo conocí aquí cuando estaba estudiando la licenciatura.
d. Parece que el niño llevó los huesos...lo dejó... y está pendiente a ver qué va a suceder.
e. Cuido los niños, mis nietos. Ya entra noche, los baño, los arreglo...todo. 
g. Pues aquí estaban jugando futbol los dos niños. Llegó la mamá y le está regañando porque rompieron un jarrón.

Los resultados se muestran en la tabla 4:

\begin{tabular}{|l|l|l|l|l|l|l|l|}
\hline \multicolumn{2}{|l|}{ Tabla 4. Reconstrucción del sistema pronominal con factor número } \\
\hline $\mathrm{N}^{\circ}$ referente & La & Las & Lo & Los & Le & Les & $\varnothing$ \\
\hline Singular & $36 / 315$ & $0 / 315$ & $229 / 315$ & $2 / 315$ & $26 / 315$ & $0 / 315$ & $22 / 315$ \\
& $11.4 \%$ & $0 \%$ & $72.7 \%$ & $0.6 \%$ & $8.2 \%$ & $0 \%$ & $7 \%$ \\
\hline Plural & $0 / 144$ & $13 / 144$ & $41 / 144$ & $74 / 144$ & $3 / 144$ & $4 / 144$ & $9 / 144$ \\
& $0 \%$ & $9 \%$ & $\mathbf{2 8 . 5} \%$ & $51.4 \%$ & $2.1 \%$ & $2.8 \%$ & $6.2 \%$ \\
\hline
\end{tabular}

(Pearson Chi-Square 274.469 p<0.000, Coeficiente de contingencia 0.596, V. de Cramer 0.524)

Los resultados de la tabla 4 ponen de relieve, con un grado moderado de asociación de las variables (0.596 y 0.524), que un porcentaje apreciable de la forma pronominal lo remite a referentes plurales, el $28.5 \%$, lo que apunta a que puede estar teniendo lugar un incipiente cambio en el que se neutralicen los rasgos de número de las formas pronominales, de manera similar al documentado con la variable género ${ }^{8}$. Abordamos, para ello, el análisis de los usos pronominales de los grupos sociales para poder concluir si la variable número está relacionada con el bilingüismo.

a. Sí, a veces cuando llegaban productos, hay que acomodarlo y todo, pero es un rato (GI).

b. Aquí arriba es una maestra, me imagino, porque tiene libros y se lo está dando al niño (GII).

c. A mí como que siempre me ha llamado la atención hacer cosas, ehhh... no sé, que sean así como retos ¿no?, y ver que yo pueda hacerlo (GIII).

d. anillos tirados, horquillas, así. Y yo lo recojo y lo pongo encima de la tele (GIV).

Los resultados se muestran en la Tabla 5.

\begin{tabular}{|l|l|l|l|l|l|l|l|l|}
\hline \multicolumn{2}{|c|}{ Tabla 5. Reconstrucción del sistema pronominal con factor número y bilingüismo } \\
\hline & & La & Las & Lo & Los & Le & Les & $\emptyset$ \\
\hline \multirow{2}{*}{ GI. } & \multirow{2}{*}{ Sing. } & $11 / 72$ & $0 / 72$ & $43 / 72$ & $1 / 72$ & $11 / 72$ & $0 / 72$ & $6 / 72$ \\
Monol. & $15.3 \%$ & $0 \%$ & $59.7 \%$ & $1.4 \%$ & $15.3 \%$ & $0 \%$ & $8.3 \%$ \\
\cline { 2 - 9 } & \multirow{2}{*}{ Plural } & $0 / 41$ & $4 / 41$ & $5 / 41$ & $27 / 41$ & $1 / 41$ & $1 / 41$ & $3 / 41$ \\
& & $0 \%$ & $9.8 \%$ & $\mathbf{1 2 . 2} \%$ & $65.9 \%$ & $2.4 \%$ & $2.4 \%$ & $7.3 \%$ \\
\hline
\end{tabular}

\footnotetext{
${ }^{8}$ Nótese, igualmente, que la frecuencia relativa de le y les para referentes plural es casi similar, $2.1 \% \mathrm{y}$ $2.8 \%$.
} 


\begin{tabular}{|c|c|c|c|c|c|c|c|c|}
\hline \multirow{2}{*}{$\begin{array}{l}\text { GII. } \\
\text { Instrum. } \\
\text { Maya L2 }\end{array}$} & Sing. & $\begin{array}{l}13 / 80 \\
16.3 \%\end{array}$ & $\begin{array}{l}0 / 80 \\
0 \%\end{array}$ & $\begin{array}{l}51 / 80 \\
63.8 \%\end{array}$ & $\begin{array}{l}0 / 80 \\
0 \%\end{array}$ & $\begin{array}{l}13 / 80 \\
16.3 \%\end{array}$ & $\begin{array}{l}0 / 80 \\
0 \%\end{array}$ & $\begin{array}{l}3 / 80 \\
3.8 \%\end{array}$ \\
\hline & Plural & $\begin{array}{l}0 / 46 \\
0 \%\end{array}$ & $\begin{array}{l}6 / 46 \\
13 \%\end{array}$ & $\begin{array}{l}7 / 46 \\
15.2 \%\end{array}$ & $\begin{array}{l}29 / 46 \\
63 \%\end{array}$ & $\begin{array}{l}2 / 46 \\
4.3 \% \\
\end{array}$ & $\begin{array}{r}0 / 46 \\
0 \%\end{array}$ & $\begin{array}{l}2 / 46 \\
4.3 \%\end{array}$ \\
\hline \multirow{2}{*}{$\begin{array}{l}\text { GIII. } \\
\text { Simétric. }\end{array}$} & Sing. & $\begin{array}{l}7 / 43 \\
16.3 \% \\
\end{array}$ & $\begin{array}{l}0 / 43 \\
0 \% \\
\end{array}$ & $\begin{array}{l}28 / 43 \\
65.1 \% \\
\end{array}$ & $\begin{array}{l}1 / 43 \\
2.3 \% \\
\end{array}$ & $\begin{array}{l}1 / 43 \\
2.3 \% \\
\end{array}$ & $\begin{array}{r}0 / 43 \\
0 \% \\
\end{array}$ & $\begin{array}{l}6 / 43 \\
14 \% \\
\end{array}$ \\
\hline & Plural & $\begin{array}{l}0 / 16 \\
0 \% \\
\end{array}$ & $\begin{array}{l}2 / 16 \\
12.5 \% \\
\end{array}$ & $\begin{array}{l}\text { 5/16 } \\
\mathbf{3 1 . 3 \%} \\
\end{array}$ & $\begin{array}{l}7 / 16 \\
43.8 \% \\
\end{array}$ & $\begin{array}{l}0 / 16 \\
0 \% \\
\end{array}$ & $\begin{array}{l}2 / 16 \\
12.5 \% \\
\end{array}$ & $\begin{array}{l}0 / 16 \\
0 \% \\
\end{array}$ \\
\hline \multirow{2}{*}{$\begin{array}{l}\text { GIV. } \\
\text { Consec. } \\
\text { Español } \\
\text { L2 }\end{array}$} & Sing. & $\begin{array}{l}5 / 120 \\
4.2 \% \\
\end{array}$ & $\begin{array}{l}0 / 120 \\
0 \% \\
\end{array}$ & $\begin{array}{l}107 / 120 \\
89.2 \%\end{array}$ & $\begin{array}{l}0 / 120 \\
0 \% \\
\end{array}$ & $\begin{array}{l}1 / 120 \\
0.8 \%\end{array}$ & $\begin{array}{l}0 / 120 \\
0 \% \\
\end{array}$ & $\begin{array}{l}7 / 120 \\
5.8 \%\end{array}$ \\
\hline & Plural & $\begin{array}{l}0 / 41 \\
0 \%\end{array}$ & $\begin{array}{l}1 / 41 \\
2.4 \%\end{array}$ & $\begin{array}{l}24 / 41 \\
58.5 \%\end{array}$ & $\begin{array}{l}11 / 41 \\
26.8 \%\end{array}$ & $\begin{array}{l}0 / 41 \\
0 \%\end{array}$ & $\begin{array}{l}1 / 41 \\
2.4 \%\end{array}$ & $\begin{array}{l}4 / 41 \\
9.8 \%\end{array}$ \\
\hline
\end{tabular}

(GI: Pearson Chi-Square 76.838 p $>0.000$, Coeficiente de contingencia: 0.636, V de Cramer 0.825. GII: Pearson Chi-Square $86.791 \mathrm{p}>0.000$, Coeficiente de contingencia: 0.639 , V de Cramer 0.830. GIII: Pearson Chi-Square 33.108 p $>0.000$, Coeficiente de contingencia: 0.600, V de Cramer 0.749. GIV: Pearson Chi-Square 44.311 p> 0.000, Coeficiente de contingencia: 0.465, V de Cramer 0.525).

Como muestran los datos de la tabla 5, parece que la neutralización del rasgo de número de las formas pronominales lo y el grado de bilingüismo son variables asociadas en un grado moderado-alto en los tres primeros grupos y moderado en el cuarto. Así, el mayor grado de bilingüismo hablantes de maya con español como L2 se corresponde con un mayor incremento de usos pronominales lo sin distinción de número, el 58.5\%. Esta tasa se reduce en el grupo de los bilingües simétricos hasta el 31.3\%; en el grupo de los bilingües incipientes con maya como L2 disminuye hasta el 15.2; finalmente, el grupo de los monolingües de español tiene la tasa más baja, el 12.2\%. Para la forma pronominal la no se documentan neutralizaciones del rasgo de número. En cuanto a los casos de leísmo, únicamente se documenta le con referentes plurales entre los monolingües y los bilingües incipientes de maya, si bien en porcentajes poco significativos, $2.4 \%$ y $4.3 \%$, respectivamente.

En vista de los resultados, es interesante destacar que la forma lo tiende a convertirse en una forma de acusativo sin especificación de género o número, y que esta tendencia se asocia fuertemente con el papel activo que la lengua maya tiene en cada grupo social. Para confirmar esto, analizamos a continuación la frecuencia relativa de la forma lo con referente femenino y con referente plural en los distintos grupos (tablas 6 y 7), que, como esperábamos, alcanza tasas ciertamente significativas en el grupo de los bilingües consecutivos de español como L2 (85.4\% y 64.9\%), lo que indica la extensión del cambio. El grado de asociación de las variables es moderado, 0491 y 0.563 para referente femenino; 0.429 y 0.475 para referente plural. 


\begin{tabular}{|l|ll|}
\hline \multicolumn{3}{|l|}{ Tabla 6. Lo con referente femenino y factor bilingüismo } \\
\hline & Lo \\
\hline GI. Monolingües & $5 / 26$ & $19.2 \%$ \\
\hline GII. Instrumental maya L2 & $10 / 32$ & $31.3 \%$ \\
\hline GIII. Simétricos & $7 / 18$ & $38.9 \%$ \\
\hline GIV. Consecutivos español L2 & $41 / 48$ & $85.4 \%$ \\
\hline N=124 (sin elisiones ni proposiciones) \\
\hline
\end{tabular}

(Pearson Chi-square 39.296 p>0.000, Coeficiente de contingencia 0.491, V. de Cramer 0.563)

\begin{tabular}{|l|ll|}
\hline \multicolumn{3}{|l|}{ Tabla 7. Lo con referente plural y factor bilingüismo } \\
\hline & Lo & \\
\hline GI. Monolingües & $5 / 38$ & $13.2 \%$ \\
\hline GII. Instrumentales & $7 / 44$ & $15.9 \%$ \\
\hline GIII. Simétricos & $5 / 16$ & $31.3 \%$ \\
\hline GIV. Consecutivos & $24 / 37$ & $64.9 \%$ \\
\hline N=135 (sin elisiones ni proposiciones) \\
\hline
\end{tabular}

(Pearson Chi-square 30.500 p $>0.000$, Coeficiente de contingencia 0.429, V. de Cramer 0.475)

Algunos casos que muestran esta tendencia se pueden ver a continuación:

(6) a. Pongo el.. la sopa a hervir...Ya una vez que está hervido, lo saco y dejo que se escurra ahí.(GI).

b. Al contrario, eso que están hablando es una lengua muy bonita, o sea, es una tradición de ellos y es imposible cambiarlo. (GII).

c. Pero creo que esa confusión no solamente lo tengo yo; también los que... también insertan esas nuevas palabras y lo usan también. (GIII).

d. Preparo la carne; lo cocino la carne; lavo trastes. (GIV).

5.4. Análisis del sistema pronominal en función de la variable "nivel de instrucción"

En las situaciones de contacto lingüístico, el nivel de instrucción de los hablantes es un factor con cierto peso a la hora de mantener, potenciar o limitar las soluciones emergentes que surgen en la comunidad de habla. Como es bien sabido, el papel que las instituciones educativas ejercen sobre las variedades emergentes no estandarizadas es muy importante, por lo que se espera una cierta correlación entre el nivel de instrucción de los hablantes y la frecuencia relativa de aparición de las soluciones emergentes. Como se describió en $\$ 4$, los hablantes de la muestra se dividieron en dos grupos en función de su nivel de estudios: con instrucción básica y media/superior. Así, esperamos que el grupo de hablantes con menor nivel de instrucción muestre los porcentajes de aparición más altos de $l o(s)$ con referentes femeninos. 
En la tabla 8 mostramos las tasas de uso de lo/s con referentes femeninos en ambos grupos. Los resultados de las pruebas estadísticas muestran que la relación de dependencia entre el factor instrucción y el género femenino del referente es significativo $^{9}$ con un grado de asociación moderado-bajo, 0.303 y 0.318 . Así, los hablantes con nivel de instrucción bajo, como esperábamos, muestran porcentajes relativos de uso de $l o / s$ con referente femenino más altos, $71.2 \%$, que los que tienen un nivel de instrucción medio-alto, 39.7\%.

\begin{tabular}{|l|ll|}
\hline \multicolumn{3}{|l|}{ Tabla 8. Pronombre lo/los con factor instrucción y referente femenino } \\
\hline & Referente femenino \\
\hline Instrucción básica & $47 / 66$ & $71.2 \%$ \\
\hline $\begin{array}{l}\text { Instrucción } \\
\text { media/superior }\end{array}$ & $23 / 58 \quad 39.7 \%$ \\
\hline $\mathrm{N}=124$ (sin elisiones ni proposiciones) \\
\hline
\end{tabular}

(Pearson Chi-square 12.505 p $>0.000$, Coeficiente de contingencia 0.303, V. de Cramer 0.318)

En (7) se muestran algunos de estos usos.

(7) a. Sale muy rápido la tortilla y tienes que acomodarlo muy rápido. (Instrucción básica).

b. No lo sé hacer. No me sale bien [las tortillas de harina]. (Instrucción media/superior).

Medimos igualmente si las variables "factor de instrucción" y "referente plural" están asociadas y favorecen la aparición de la forma lo. En efecto, ambas variables mostraban significancia estadística con un grado de asociación moderado-bajo; la forma emergente alcanza una tasa del $45.2 \%$ en el grupo con instrucción básica y del $17.8 \%$ en el grupo de instrucción medio-alto. Los resultados se muestran en la tabla 9.

\begin{tabular}{|l|l|}
\hline \multicolumn{2}{|l|}{ Tabla 9. Pronombre lo con factor instrucción y referente plural } \\
\hline & Referente plural \\
\hline Instrucción básica & $28 / 62 \quad 45.2 \%$ \\
\hline $\begin{array}{l}\text { Instrucción } \\
\text { media/superior }\end{array}$ & $13 / 60 \quad 17.8 \%$ \\
\hline $\mathrm{N}=135$ (sin elisiones ni proposiciones) \\
\hline
\end{tabular}

(Pearson Chi-square $11.862 \mathrm{p}>0.001$, Coeficiente de contingencia 0.284, V. de Cramer 0.296)

Algunos casos de lo con referente plural se muestran en (8):

\footnotetext{
${ }^{9}$ En la tabla solo se muestran los resultados de los referentes femeninos, aunque el análisis se efectuó con ambos géneros. Las variables "referente femenino" y "nivel de instrucción" resultaron significativas estadísticamente, esto es, asociadas; no así las variable "referente masculino" y "nivel de instrucción".
} 
(8) a. Dos banquillos agarro así... lo pongo así. (Instrucción básica).

b. Parece que el niño llevó los huesos... lo dejó... y está pendiente a ver qué va a suceder (Instrucción media/superior).

5.5. Análisis del sistema pronominal en función de variables gramaticales y discursivas Hasta este momento, hemos reconstruido los sistemas pronominales de los distintos grupos sociales de la muestra y hemos constatado la existencia de un cambio en progreso hacia la forma lo como única forma de acusativo, sin distinción morfológica de género o número, esto es, un proceso en el que los pronombres se gramaticalizan como concordancias de objeto. Por ello, pretendemos averiguar, a continuación, si este cambio sigue los parámetros basados en las escalas de topicidad (Givón, 1976) propuestos en la bibliografía para explicar este tipo de gramaticalizaciones (Girón Alconchel 2002, Vivanco 2103, Belloro 2012, Gómez Seibane 2012, Huerta 2005, entre otros); esto es, contextos de alto grado de topicidad de los referentes en los que la animacidad, la definitud o la especificidad juegan un papel relevante. Así, analizamos a continuación la incidencia de las variables gramaticales "animacidad", "definitud" o "especificidad" del referente en la aparición de las formas emergentes en estudio, así como los contextos discursivos en los que estas formas aparecen.

\subsubsection{Variables gramaticales/discursivas y género del referente}

Como se ha mostrado hasta ahora, la variable mono/bilingüismo favorece la aparición de las formas emergentes, sin embargo no todos los grupos presentan tasas similares de aparición de estas formas. Dado que el grupo de hablantes bilingües consecutivos de español como L2 tiene más de un $80 \%$ de formas $l o / s$ con referente femenino, consideramos que estas formas son, de hecho, las no marcadas y, por tanto, suponemos que las variables gramaticales y discursivas independientes no condicionarán su aparición, como sucede con las variables "género del referente" y "bilingüismo", que no están asociadas en este grupo debido a que el cambio está ampliamente extendido (tabla 2). Por el contrario, los grupos de hablantes monolingües de español, bilingües con maya incipiente como L2 y bilingües simétricos presentan frecuencias relativas más bajas que indican que el cambio aún no está consolidado en estos grupos; por ello, esperamos encontrar precisamente en estos grupos variables gramaticales y discursivas que favorezcan la aparición de las formas emergentes y que permitan, por ello, esbozar 
una explicación de cómo se ha iniciado el cambio lingüístico, pues creemos que este no es azaroso o caótico. Esta es la razón que justifica que hayamos unido estos tres grupos en el análisis de las variables gramaticales que presentamos a continuación. En definitiva, reagrupamos la muestra en Grupo I (monolingües de español, bilingües con maya incipiente como L2 y bilingües simétricos) y Grupo II (bilingües consecutivos con español como L2) y realizamos un análisis bivariado de tablas de contingencia para establecer si las variables gramaticales y discursivas son significativas estadísticamente $\mathrm{y}$ favorecen la aparición de las formas emergentes ${ }^{10}$.

Analizamos, en primer lugar, si el rasgo [ \pm humano] del referente, el más prominente en la escala de animacidad, favorece la aparición de las formas emergentes. Los resultados estadísticos indican que esta variable, en efecto, está asociada a las formas emergentes únicamente en el Grupo I, con un grado de asociación moderado-bajo ( 0.325 y 0.344); esto es, que $l o / s$ se favorece cuando las entidades son [-humanas], 47.1\%, pero no cuando son [+humanas], 12\%. En el GII el cambio está tan extendido que los hablantes no seleccionan estas formas novedosas en función del rasgo [ \pm humano] del referente.

(9) a. Pues si le tiraron la basura, pues la obligación de uno es volverlo a recoger. (GI).

b. O sea, yo he visto en las noticias que hay personas que no se pueden expresar, o sea, los discriminan. (GI).

c. Ya lo llevaron la niña. Quién sabe dónde lo llevaron. (G II).

d. Antes que entre ya ella ya sabe escribir; las vocales ya lo sabe escribirlo. (G II). Los resultados se muestran en la tabla 10.

\begin{tabular}{|l|l|ll|ll|}
\hline \multicolumn{7}{|l|}{ Tabla 10. Mono/bilingüismo y referente [ \pm humano] (con referente femenino) } \\
\hline Mono/bilingüismo & \pm Humano & Lo/los & \multicolumn{2}{l|}{ Resto formas } \\
\hline \multirow{2}{*}{ GI } & + humano & 3 & $12 \%$ & 22 & $88 \%$ \\
\cline { 2 - 6 } & -humano & 24 & $\mathbf{4 7 . 1 \%}$ & 27 & $52.9 \%$ \\
\hline \hline \multirow{2}{*}{ GII } & +humano & 11 & $78.6 \%$ & 3 & $21.4 \%$ \\
\cline { 2 - 6 } & -humano & 32 & $94.1 \%$ & 2 & $5.9 \%$ \\
\hline $\mathrm{N}=124$
\end{tabular}

(Grupo I: Pearson Chi-square: 9.002 p> 0.002, Coeficiente de contingencia 0.325, V. de Cramer 0.344).

\footnotetext{
${ }^{10} \mathrm{El}$ análisis cuantitativo de las formas emergentes, sin especificación de género ni de número, se realizó con las formas pronominales que remitían a entidades masculinas y femeninas; los casos de elisión, cuya forma pronominal es imposible reconstruir, se excluyeron de la muestra así como las formas pronominales cuyo antecedente es la oración anterior.
} 
Siguiendo la misma escala de animacidad, analizamos seguidamente si el rasgo $[ \pm$ animado] del referente supone un condicionante favorecedor de la aparición de las formas emergentes $l o / s$ con referente femenino en los dos grupos descritos. El resultado es que las variables están asociadas en el Grupo I, si bien con un grado de asociación moderado-bajo (0.290 y 0.303 ), esto es, los objetos prototípicos [-animados] favorecen la aparición de las formas emergentes. En el Grupo II las formas emergentes no están asociadas a variables gramaticales, lo que significa que en este grupo la aparición de lo/s se da tanto si el referente es animado como inanimado.

(10) a. El primer contacto que tú estableces con la persona, si es en español...como que ya lo defines, y la próxima vez que lo ves también le vas a hablar en español aunque sepa maya. (GI).

b. Y ya de allá, yo vendía mi fruta; y ya de allá, me animé a vender la ropa. Y ya lo seguía vendiendo. (GII).

Los resultados se muestran en la tabla 11:

\begin{tabular}{|l|l|ll|ll|}
\hline \multicolumn{7}{|l|}{ Tabla 11. Mono/bilinguismo y animacidad con $l o / s$ vs. y resto pronombres (referente femenino) } \\
\hline Mono/bilingüismo & Animacidad & \multicolumn{2}{l}{ Lo/Los } & \multicolumn{2}{l|}{ Resto formas } \\
\hline \multirow{2}{*}{ GI } & + animados & 4 & $15.4 \%$ & 22 & $84.6 \%$ \\
\cline { 2 - 7 } & -animados & 23 & $\mathbf{4 6 \%}$ & 27 & $54 \%$ \\
\hline \hline \multirow{2}{*}{ GII } & + animados & 13 & $81.3 \%$ & 3 & $18.8 \%$ \\
\cline { 2 - 7 } & -animados & 30 & $93.8 \%$ & 4 & $6.3 \%$ \\
\hline $\mathrm{N}=124$ &
\end{tabular}

(Grupo I: Pearson Chi-square: 7.000 p> 0.007, Coeficiente de contingencia 0.290, V. de Cramer 0.303).

Siguiendo las escalas de topicidad de los referentes, analizamos a continuación si la definitud o la especificidad del referente favorecen la aparición de las formas emergentes; sin embargo, solo la variable "definitud" resulta significativa estadísticamente. La definitud, como es bien sabido, interviene en otros fenómenos relacionados con el sistema pronominal átono como la omisión, la duplicación de OD o el marcado diferencial de objeto directo preposicional. En efecto, el análisis de los datos indica que la variable "[+definido]" está asociada con la variable "Grupos" con un grado de asociación moderado (0.494 y 0.568$)$, es por tanto significativa estadísticamente. Es interesante observar que el GII tiene una tasa de aparición de formas emergentes muy alta, el $90.5 \%$, frente al $32.8 \%$ que presenta el GI, lo que parece reflejar bien el origen y la extensión del cambio en estos grupos. 


\begin{tabular}{|l|l|ll|lc|}
\hline Tabla 12. Definitud con lo/s vs. y resto pronombres (referente femenino) \\
\hline Definitud & Mono-bilingüismo & Lo/Los & \multicolumn{2}{l|}{ Resto formas } \\
\hline \multirow{2}{*}{ +Definido } & GI & 21 & $\mathbf{3 2 . 8 \%}$ & 43 & $67.2 \%$ \\
\cline { 2 - 6 } & GII & 38 & $\mathbf{9 0 . 5 \%}$ & 4 & $9.5 \%$ \\
\hline \hline \multirow{2}{*}{-Definido } & 6 & $50 \%$ & 6 & $50 \%$ \\
\cline { 2 - 6 } & GI & 5 & $83.3 \%$ & 1 & $16.7 \%$ \\
\hline \multirow{2}{*}{$\mathrm{N}=124$} & GII & 5 & \multicolumn{3}{l}{} \\
\hline
\end{tabular}

([+Definidos]: Pearson Chi-square: 34.166 p>0.000, Coef. de contingencia 0.494, V. de Cramer 0.568).

(11) a. ¿Y practicas pesca? -Ah, sí, lo hemos practicado. (GI).

b. Está viendo televisión. El papá le dice...que lo apague. (GII)

c. No lo encontraron [la niña]. Empezaron a buscar de noche, no lo encontraron. (GII).

d. Yo digo que sí porque ahorita hay muchas cosas que te tan dando en maya y no lo entiendes. (GII).

Otras variables que se han relacionado con la gramaticalización de los pronombres como la topicidad del sujeto, que este sea [ \pm humano], no resultan significativas estadísticamente en nuestro estudio, como tampoco la especificidad del referente. El rasgo [+continuo] del referente, por el contrario, sí favorece la aparición de lo/s en el Grupo I, aunque en un grado bajo (0.246 y 0.254), como se muestra en la tabla 13. En el Grupo II, las entidades continuas son referidas de manera categórica por las formas emergentes, mientras que las discontinuas tienen una frecuencia relativa de uso de estas formas del $87.5 \%$, lo que permite dar una idea de la extensión del cambio.

\begin{tabular}{|l|l|ll|lc|}
\hline \multicolumn{7}{|l|}{ Tabla 13. Mono/bilinguismo y continuidad del referente (referente femenino) } \\
\hline Mono/bilingüismo & Continuidad & Lo/Los & \multicolumn{2}{l|}{ Resto formas } \\
\hline \multirow{2}{*}{ GI } & + continuo & 9 & $\mathbf{6 0 \%}$ & 6 & $40 \%$ \\
\cline { 2 - 6 } & -continuo & 18 & $29.5 \%$ & 43 & $70.5 \%$ \\
\hline \hline \multirow{2}{*}{ GII } & + continuo & 8 & $100 \%$ & 0 & $0 \%$ \\
\cline { 2 - 6 } & -continuo & 35 & $87.5 \%$ & 5 & $12.5 \%$ \\
\hline $\mathrm{N}=124$ &
\end{tabular}

(Grupo I: Pearson Chi-square: 4.887 p>0.030, Coeficiente de contingencia 0.246, V. de Cramer 0.254).

(12) ¿a. ¿Y así quién lo recoge? ¿Lo vuelven a recoger sus dueños? [la basura tirada]. (GI).

b. ¿Compra usted la ropa en la Zona libre? -No, se lo compro a personas que vienen a vender su ropa. (GII).

El rasgo [ \pm continuo] ha sido relevante para explicar algunos de los sistemas pronominales átonos de España y de otras lenguas romances (Fernández-Ordóñez 2001, 
2006 y 2007). Según la autora (2001: 443), "las entidades discontinuas ofrecen mayor versatilidad sintáctica: son sintácticamente tanto objetos directos como indirectos, mientras que las continuas son fundamentalmente objetos directos. [...], constituyen una clase de mayor amplitud semántica: las entidades discontinuas pueden ser animadas o inanimadas, mientras que las entidades continuas son siempre inanimadas". Los resultados de nuestro análisis nos llevan a proponer que son precisamente los objetos prototípicos, entidades [-humanas], [-animadas], [+definidas] y [+continuas], los que parecen más sensibles a favorecer las formas emergentes en el GI. Así, el cambio en progreso se extiende desde el GII al GI a partir de las entidades prototípicas.

Para finalizar esta sección, analizamos un factor que se ha considerado fundamental en el estudio de las formas pronominales en los últimos años: la accesibilidad y persistencia del referente (Ariel 1990, Givón 1983, Belloro 2008 y 2012, Gómez Seibane 2012, entre otros). Según estos estudios, las formas que muestran mayor atenuación fonética o morfológica son las que tienen mayor accesibilidad del referente, por lo que esperamos que las formas emergentes de nuestro estudio aparezcan preferentemente en contextos con referentes más accesibles. Para corroborar si esto es así, dividimos la muestra en tres contextos pragmáticos relacionados con la accesibilidad y la persistencia del referente: a) casos en los que el referente está tematizado a la izquierda, formas topicalizadas prototípicas que muestran un alto grado de activación, por lo que pueden ser referidas con formas atenuadas (Toole $1996 \mathrm{y}$ Walker y Prince 1996); b) casos de duplicación, donde el referente parece tener un grado de activación mayor que los objetos prototípicos (Belloro 2012); c) casos en los que el referente está mencionado en el contexto inmediatamente anterior o en los que hay una persistencia referencial y se convierte en tópico de discurso. Según esto, medimos si esta variable puede tener incidencia en la selección de las formas emergentes.

(13) a. Y nosotros nos llevan. Allá mi difunta mamá lo llevan a hacer... comida allá (GII).

b. Con eso que..que me gustaría hacer mis ropas para hacer... para hacerlos al modelo que a mí me guste (GI).

c. Lo está vendiendo la grabadora (GI).

d. Pienso cómo lo voy a hacer las cuentas (GII). 
e. Entró el tigre y lo jaló la... niña y lo llevó en el monte. Ya lo llevaron la niña. Quién sabe dónde lo llevaron. No lo encontraron. Empezaron a buscar de... de noche... no lo encontraron (GII).

f. Estoy viendo que hay un niño que le está haciendo maldad a su hermanita; le está quitando su muñeca y la niña se lo está pidiendo (GII).

Los resultados se muestran en la tabla 14.

\begin{tabular}{|l|l|lc|lc|}
\hline \multicolumn{6}{|l|}{ Tabla 14. Accesibilidad y mono/bilingüismo (referente femenino) } \\
\hline $\begin{array}{l}\text { Accesibilidad } \\
\text { referente }\end{array}$ & Mono/bilingüismo & \multicolumn{2}{l|}{ Lo/Los } & \multicolumn{2}{l|}{ Resto formas } \\
\hline \multirow{2}{*}{ Tematización } & GI & 3 & $37.5 \%$ & 5 & $62.5 \%$ \\
\cline { 2 - 7 } & GII & 4 & $57.1 \%$ & 3 & $42.9 \%$ \\
\hline \hline \multirow{2}{*}{ Duplicación } & GI & 1 & $16.7 \%$ & 5 & $83.3 \%$ \\
\cline { 2 - 7 } & GII & 9 & $100 \%$ & 0 & $0 \%$ \\
\hline \hline \multirow{2}{*}{ Tópico de discurso } & GI & 23 & $37.1 \%$ & 39 & $62.9 \%$ \\
\cline { 2 - 7 } & GII & 30 & $\mathbf{9 3 . 8} \%$ & 2 & $6.3 \%$ \\
\hline $\mathrm{N}=124$ & \multicolumn{7}{l}{} \\
\hline
\end{tabular}

(Duplicación: Pearson Chi-square 11.250 p >0.002, Coeficiente de contingencia 0.655, V. de Cramer 0.866). (Tópico disc.: Pearson Chi-square: 27.546 p>.000, Coeficiente de contingencia 0.476, V. de Cramer 0.541).

Los resultados muestran que los contextos de duplicación y tópico de discurso están asociados estadísticamente con las formas emergentes en ambos grupos, con un grado de asociación moderado-alto en el caso de la duplicación y moderado en el de tópico de discurso, a diferencia de los contextos de tematización, que no resultaron significativos estadísticamente para ninguno de los grupos. Así, la mayor continuidad del referente se corresponde con las formas novedosas más gramaticalizadas. En el caso del GII, el contexto de tópico de discurso arroja una tasa de aparición ciertamente alta, el 93.8\%, que llega a ser categórica en los contextos de duplicación, el 100\% de formas lo/s. Estos resultados permiten pensar que en este grupo el cambio casi se ha consolidado por completo. En cuanto al GI, los hablantes crean más formas emergentes en contextos de tópico de discurso, el $37.1 \%$, si bien la frecuencia de aparición está muy alejada de la del GII.

\subsubsection{Variables gramaticales/discursivas y número del referente}

Como se ha señalado sobradamente, el proceso de gramaticalización de las formas pronominales de dativo tiene lugar desde el español medieval hasta nuestros días. Uno de los rasgos que se aducen al respecto para mostrar el grado de gramaticalización de 
estas formas es la aparición cada vez más frecuente de le con referentes plurales (Becerra Bascuñán 2007, Bogard 1992, De Mello 1992, Company 2001, Fernández Soriano 1999, Huerta 2005, Belloro 2012, Sorenson 2013; Soto, Sadowsky y Martínez 2014, entre otros), esto es, la pérdida de su valor referencial y, por tanto, su mayor gramaticalización (¿no quieres darle un bocadillo a tus hijos? Puede que se hayan quedado con hambre). En este sentido, hay que decir que el español de la zona maya no es ajeno a esta tendencia. Hernández (en prensa) pone de manifiesto que el 37.7\% de las formas de dativo con referente plural se materializa mediante la forma le, una tasa inferior a la que presentan otros estudios (véase, por ejemplo, Huerta 2005, que registra tasas del 57\%, o Sorenson 2014, que reporta 39.2\% en 11 ciudades de habla española, incluido el DF, México). Lo particular del caso es que esta frecuencia relativa de uso muestra, según Hernández, una gradación considerable en función del grado de mono/bilingüismo de los hablantes: monolingües de español, $31.6 \%$; bilingües de maya incipiente como L2, 31.6\%; simétricos en ambas lenguas, 36\%; consecutivos de español como L2, 61.9\%. Concluye la autora que, si bien estamos ante un proceso de gramaticalización general, la influencia de la lengua maya incrementa considerablemente el cambio en proceso, disparando las tasas de aparición de las formas emergentes. Véase, como ejemplo, las emisiones siguientes que contienen formas de dativo le con referentes plurales:

(14) a. Pues yo creo que...está bien que le enseñen a otras personas a hablar maya [los mayahablantes] (H. monolingüe).

b. Y aquí pues son personas que están en la playa, me imagino que de vacaciones, y el otro que le está tomando foto (H. bilingüe incipiente de maya).

c. Cuando ellos conquistan a las muchachas, ¿no? Lo primero lo hacían en español porque en español también hay más palabras... para poder decirle a las muchachas (H. mujer bilingüe simétrico).

d. Hay unos muchachos, y pienso que le están dando agua caliente [unas muchachas] (H. bilingüe consecutivo).

Teniendo esto en cuenta, pasamos a continuación a analizar la neutralización del rasgo de número de las formas pronominales en función del grado de bilingüismo, que, como mostramos en la tabla 5 , son variables asociadas. 
Siguiendo una metodología similar a la empleada para analizar las formas emergentes con referente femenino, hemos agrupado los hablantes de nuestra muestra en dos grupos: GI (monolingües de español, bilingües de maya incipiente como L2 y bilingües simétricos) y Grupo II (bilingües consecutivos de español como L2). A continuación presentamos un primer análisis cuantitativo donde medimos si las formas $l o / l e^{11}$ con referente plural versus las/los/les son significativas estadísticamente en relación con los grupos I y $\mathrm{II}^{12}$. Es preciso recordar que (véase la tabla 5), a diferencia del resto de grupos englobados en GI, en el GII no se documentaron casos de le con referente plural, todos los casos son de lo con referente plural. Los resultados se muestran en la tabla 15:

\begin{tabular}{|l|ll|lc|}
\hline \multicolumn{5}{|l|}{ Tabla 15. Referente plural y mono/bilingüismo } \\
\hline Mono/bilingüismo & Lo/Le & Las/Los/Les \\
\hline GI & 20 & $20.4 \%$ & 78 & $79.6 \%$ \\
\hline GII & 24 & $\mathbf{6 4 . 9} \%$ & 13 & $35.1 \%$ \\
\hline $\mathrm{N}=135 / 428$ (sin proposiciones ni elisiones) \\
\hline
\end{tabular}

(Pearson Chi-square 24.163 p>.000, Coeficiente de contingencia 0.390, V. de Cramer 0.423)

Los estadísticos permiten mostrar, con un grado de asociación moderado-bajo (0.390 y 0.423), que el GII favorece considerablemente las formas pronominales lo con referentes plurales, el 64.9\% (no hay casos de le con referentes plurales). El GI, por el contrario, muestra un porcentaje considerablemente menor de formas emergentes, el $20.4 \%$.

(15) a. No lo sé hacer. No me sale bien [las tortillas de harina] (GI).

b. El orden, la disciplina... que son cosas que también son muy buenas y que quizás debemos adoptarlo. Pues solamente decía, bueno, tenemos que adoptarlo pero de acuerdo con las características culturales. (GII).

Siguiendo con las escalas de topicidad, que resultaron significativas en el estudio de las formas emergentes con referentes femeninos, analizamos en primer lugar si el grado más altamente topical del referente, el rasgo [ \pm humano], favorece la aparición de las nuevas formas. Los resultados, en la tabla 16, muestran que las variables están asociadas estadísticamente solo en el rasgo [-humano], con un grado de asociación moderado

\footnotetext{
${ }^{11}$ En la muestra no se documentó la forma la con referentes plurales.

12 Siguiendo la misma metodología, en este análisis no incluimos los casos de elisión dado que no podemos reconstruir su forma pronominal. Tampoco incluimos los casos que remiten a una proposición.
} 
(0.391 y 0.425$)$, lo que implica que ambos grupos favorecen las formas emergentes con entidades [-humanas] aunque con distinta tasa de aparición, 40.5\% el GI, 84\% el GII.

\begin{tabular}{|c|c|c|c|c|c|}
\hline \multicolumn{6}{|c|}{ Tabla 16. $[ \pm$ Humano] con lo y le (referente plural) vs. resto pronombres } \\
\hline \pm Humano & & Lo & & $\operatorname{Re}$ & \\
\hline \multirow{2}{*}{ +Humano } & GI (mono) & 3 & $5.4 \%$ & & $94.6 \%$ \\
\hline & GII & 3 & $25 \%$ & 9 & $75 \%$ \\
\hline \multirow[t]{2}{*}{-Humano } & GI (mono & & $40.5 \%$ & 25 & $59.5 \%$ \\
\hline & GII & 21 & $84 \%$ & 4 & $16 \%$ \\
\hline
\end{tabular}

([-humano]: Pearson Chi-square 12.093 p $>0.000$, Coeficiente de contingencia 0.391, V. de Cramer 0.425)

En (16) se muestran algunos casos de estos usos:

(16) a. Ajá, tienen agarrados sus libros, enseñándolo. (GI).

b. Veo a dos niños y a su mamá que lo está regañando porque quebraron un florero (GI).

c. Porque esas iglesias que se han construido, lo han construido los norteamericanos. (GII).

d. Ah, la mamá lo está regañando, ¿verdad? [a los niños] (GII).

Analizamos a continuación si la variable animacidad del referente puede favorecer igualmente la aparición de las formas lo/le con referente plural. Como se aprecia en la tabla 17, el rasgo [-animado] del referente resulta significativamente estadístico en la selección de las formas emergentes con un grado de asociación de las variables moderado, si bien con una diferencia considerable: el GI favorece estas formas en el 43.8\% de las apariciones y el GII en el 83.3\% de los casos. Nótese, nuevamente, cómo en el GII las nuevas formas son mayoritarias.

\begin{tabular}{|c|c|c|c|c|c|}
\hline \multicolumn{5}{|c|}{ Tabla 17. Animacidad con lo y le (referente plural) vs. resto pronombres } & \\
\hline \multirow[t]{2}{*}{ +Animado } & GI & & $9.1 \%$ & 60 & $90.9 \%$ \\
\hline & GII & 4 & $30.8 \%$ & 9 & $69.2 \%$ \\
\hline \multirow[t]{2}{*}{-Animado } & GI & 14 & 43.8\% & 18 & $56.3 \%$ \\
\hline & GII & 20 & $83.3 \%$ & 4 & $16.7 \%$ \\
\hline
\end{tabular}

[-animados]: Pearson Chi-square 9.009 p > 0.003, Coeficiente de contingencia 0.372, V. de Cramer 0.401).

Un ejemplo de cada grupo puede apreciarse en (17):

(17) a. Y ¿qué pasa? -Pues no lo comen. Los huesitos ahí siguen (GI).

b. Lo consumo y lo vendo [los productos] (GII). 
La definitud del referente -a diferencia de la especificidad, que no fue significativa estadísticamente en nuestro caso- es un rasgo que se ha mostrado relevante en la variación de los sistemas pronominales. En el caso que nos ocupa, la variable entidad [+definida] se asocia estadísticamente con la selección de las formas emergentes, si bien con frecuencias de aparición relativa muy distintas: el 60.7\% en el GII y el 17.9\% en el GI; con entidades [-definidas] hay también una tasa de aparición muy alta, el 77.8\% y el $35.7 \%$ respectivamente, si bien el número de casos es muchísimo menor. El grado de asociación de estas variables es, como se aprecia en la tabla 18, moderado (0.380 y $0.411)$.

\begin{tabular}{|l|l|ll|lc|}
\hline \multicolumn{7}{|l|}{ Tabla 18. Definitud con lo y le (referente plural) vs. resto pronombres } \\
\hline Definitud & & Lo/Le & \multicolumn{3}{l|}{ Resto } \\
\hline +Definido & GI & 15 & $17.9 \%$ & 69 & $82.1 \%$ \\
\cline { 2 - 7 } & GII & 17 & $60.7 \%$ & 11 & $39.3 \%$ \\
\hline \hline \multirow{2}{*}{-Definido } & GI & 5 & $35.7 \%$ & 9 & $64.3 \%$ \\
\cline { 2 - 7 } & GII & 7 & $77.8 \%$ & 2 & $22.2 \%$ \\
\hline $\mathrm{N}=135$ & \multicolumn{7}{|l|}{} \\
\hline
\end{tabular}

[+Definidos]. Pearson Chi-square $18.900 \mathrm{p}>0.000$, Coeficiente de contingencia 0.380, V. de Cramer $0.411)$.

A continuación, mostramos algunos ejemplos de ambos grupos:

(18) a. Supongo que les puso la, los huesitos ahí pensando que los gatitos lo iban a comer, pero no sucedió así (GI).

b. Aquí arriba es una maestra, me imagino, porque tiene libros y se lo está dando al niño (GI).

c. A veces pega los niños, lo pellizcaba o si no, le hace travesuras (GII).

d. Hay una maestra con unos libros...Lo repartió a los niños (GII).

Para finalizar esta sección ${ }^{13}$, analizamos si la accesibilidad del referente es significativa en la selección de lo/le con referente plural. En efecto, las variables están asociadas estadísticamente, con un grado moderado-bajo de asociación $(0.371,0.399)$ en contexto de tópico de discurso, altamente topical, que favorece, como esperábamos, la aparición de las nuevas formas en el GII, 57.1\%, frente al $42.9 \%$ de formas conservadoras. En el caso de la duplicación, prototípico de la concordancia de objeto, este grupo muestra tasas categóricas, $100 \%$ de formas emergentes, como ocurría en el caso de las formas

\footnotetext{
${ }^{13}$ La continuidad del referente no resultó estadísticamente significativa.
} 
novedosas sin especificación de género, lo que significa que este contexto favorece siempre estas formas. Los casos de tematización no resultaron significativos estadísticamente. En el GI, las formas emergentes aparecen mayoritariamente en contextos de duplicación, si bien los casos son muy pocos como para que resulten significativos; en otros contextos, este grupo favorece las formas más conservadoras. Los resultados se muestran en la tabla 19.

\begin{tabular}{|c|c|c|c|c|c|}
\hline Accesibilidad & Mono/bilingüismo & & & Res & \\
\hline \multirow[t]{2}{*}{ Tematización } & GI & 4 & $44.4 \%$ & 5 & $55.6 \%$ \\
\hline & GII & 3 & $75 \%$ & 1 & $25 \%$ \\
\hline \multirow[t]{2}{*}{ Duplicación } & GI & 2 & $66.7 \%$ & 1 & $33.3 \%$ \\
\hline & GII & 5 & $100 \%$ & 0 & \\
\hline \multirow[t]{2}{*}{ Tópico de discurso } & GI & 14 & $16.3 \%$ & 72 & $83.7 \%$ \\
\hline & GII & 16 & $57.1 \%$ & 12 & $42.9 \%$ \\
\hline
\end{tabular}

(Tópico del discurso: Chi-square 18.190 p> 0.000. Coeficiente de contingencia 0.371, V de Cramer 0.399).

Es evidente que las formas emergentes con referente plural -como ocurría con $\mathrm{lo} / \mathrm{s}$ femenino- cuyas características son [-animadas], [+definidas], se favorecen en contextos de tópico de discurso. Los contextos de duplicación seleccionan categóricamente las nuevas formas sin especificación de plural en el GII y son mayoritarias en el GI. Esto supone que son los objetos prototípicos altamente topicales de gran accesibilidad los candidatos a ser anticipados por una concordancia de objeto en el verbo sin especificación de los rasgos de número del referente: $l o$.

En definitiva, las formas emergentes sin especificación de género o número son mayoritarias en el GII, lo que indicaría que este grupo prácticamente habría completado el cambio hacia lo como concordancia de objeto, independientemente de rasgos léxicos, sintácticos o pragmáticos de sus referentes. Por su parte, los datos muestran que el GI empieza a abrir su sistema al cambio a partir de los objetos prototípicos de acusativo: inanimados y definidos en contextos altamente accesibles; son estas entidades prototípicas las que favorecen estadísticamente las formas emergentes.

\section{El maya yucateco}

En maya yucateco no se marca el género gramaticalmente, aunque se distingue el sexo masculino y femenino mediante el uso de las partículas: aj para masculino, e (i)x para 
femenino. No obstante, la forma masculina se puede usar como marcador general y neutral de sexo (Yoshida, 2014:23).
a. aj ka'ansaj "maestro" / x ka'ansaj "maestra"
b. aj kíimsaj "matador, asesino"
c. aj chuuy "sastre" / x chuuy "costurera"
d. aj k'aay "cantante" / x k'aay "cantante" (mujer)

También se distingue el sexo mediante formas lexicalizadas:
a. xiib hombre
b. ko'olel mujer
c. xi'ipal muchacho
d. ch'úupal muchacha

Para los animales, se anteponen las palabras xibil o ch'upul si se refiere a un macho o a una hembra, respectivamente (Yoshida, 2013):

(21) a. Wakax ganado vacuno $\rightarrow$ xibil wakax toro o ch'upul wakax vaca

b. Tsíimin ganado equino $\rightarrow$ xibil tsíimin caballo o ch'upul tsíimin yegua

En cuanto al número, la pluralización se señala en los sustantivos y adjetivos mediante el sufijo $-o$ 'ob. La concordancia no es obligatoria cuando tenemos sustantivos y adjetivos juntos; sólo el sustantivo puede pluralizarse. (Yoshida, 2013):
a. Nojoch grande + kuum olla $\rightarrow$ nojoch kuumo'ob ollas grandes
b. Taam profundo + ch'e'en pozo $\rightarrow$ taam ch'e'eno'ob pozos profundos

Según (Yoshida, 2014), el grupo de pronombres que se utilizan para marcar al objeto directo paciente de una oración transitiva son los siguientes:

\begin{tabular}{|l|l|l|}
\hline Persona & Singular & Plural \\
\hline $1^{\mathrm{a}}$. & -en & -o'on \\
$2^{\mathrm{a}}$. & $-\mathrm{ech}$ & -e'ex \\
$3^{\mathrm{a}}$. & $-\varnothing$ & -o'ob \\
\hline
\end{tabular}

Cabe aclarar que en la tercera persona del plural la marca es el cero fonético; lo que aparece en la tabla es el sufijo de plural. Veamos los siguientes ejemplos de Yoshida (2014:24):
a. Jaanen 'comí'.
b. Ku jaantikech 'te come'. 


\author{
c. Ku jaantik-! le kaaxo' 'come la gallina'. \\ d. Ku jaantik-! 'la come'.
}

\title{
7. La discusión
}

Como hemos mostrado en secciones anteriores, en las variedades de español en contacto con maya de hablantes monolingües de entorno maya y en bilingües de español y maya, el sistema pronominal átono de tercera persona está experimentando un cambio en progreso: la gramaticalización de formas pronominales como concordancias de objeto, que se manifiesta en la tendencia hacia el uso de formas pronominales sin especificación de género y número. Estas formas se despronominalizan, pierden sus capacidades deícticas y se convierten en marcas de concordancia de objeto: le para objeto indirecto y lo para directo. Esto supone que se está produciendo la reorganización, y recategorización, del sistema, como apuntábamos.

Hemos constatado, igualmente, que este cambio en progreso está en estrecha relación con el grado de conocimiento que los hablantes tienen de la lengua maya. Así, se documenta que en el grupo de los bilingües consecutivos de español, las formas con neutralización del rasgo de género y de número se han convertido en las formas no marcadas, por lo que el cambio se ha extendido casi por completo, el $85.4 \%$ (tabla 6) y el $64.9 \%$ (tabla 7) respectivamente; así, las formas emergentes, con baja capacidad referencial, se consolidan como formas mayoritarias apenas condicionadas por variables lingüísticas (con excepción de la definitud y el contexto discursivo), debido precisamente a su amplia extensión. El resto de los grupos muestran tasas de uso decrecientes de ambas formas emergentes en función del grado de dominio de la lengua maya. Así, el grupo de los bilingües simétricos tiene una tasa del 38.9\% de formas sin diferenciación de género y del $31.3 \%$ de formas sin especificación de número. En el grupo de los bilingües incipientes de maya estas tasas de uso se rebajan ligeramente para las formas sin diferenciación de género, $31.3 \% \%$, y se reducen hasta la mitad en el caso del número, 15.9\%. Finalmente, el grupo de los monolingües de ambiente bilingüe es el que presenta tasas más bajas de aparición de las formas en estudio, 19.2\% para formas sin distinción de género y 13.2\% para aquellas que no diferencian el número. 
Estos datos permiten concluir que el cambio se origina en el grupo de los bilingües consecutivos de español y se expande progresivamente hacia los otros grupos. Podemos decir, en este sentido, que se trata de un cambio lingüístico que obedece a factores externos, esto es, que está inducido por el contacto con la lengua maya. Hemos visto también que el nivel de instrucción también está asociado a la variación lingüística; así, el grupo con nivel de instrucción básico tiene una tasa de uso de formas emergentes sin distinción de género del $71.2 \%$, a diferencia del 39.7\% que presenta el grupo que tiene un nivel de instrucción media-alta. En cuanto a las formas sin especificación de número, la diferencia aumenta ligeramente entre grupos: $45.2 \%$ versus $17.8 \%$ para el grupo con instrucción básica y media-alta, respectivamente. Es preciso señalar que el nivel de instrucción es un poderoso medidor del grado de prestigio o desprestigio de estas formas, ya que cuanto mayor sea el tiempo de permanencia de los individuos en la institución educativa, mayor probabilidad tendrán estos de abandonar usos considerados poco prestigiosos, como es el caso de las formas emergentes.

Volviendo a la dinámica interna del cambio en progreso, es preciso averiguar qué entidades son las que parecen más sensibles a acoger las formas emergentes. Como argumentamos en la sección anterior, este análisis debe hacerse en los grupos con mayor variación entre formas canónicas y emergentes, esto es, en hablantes monolingües de español, bilingües incipientes de maya y bilingües simétricos, donde las tasas de uso de las formas emergentes están por debajo del 50\%. Por el contrario, el grupo de bilingües consecutivos de español muestra una tasa de variación muy pequeña en el caso de las formas emergentes sin distinción de género $(7.8 \%$ de formas etimológicas, $2 \%$ de leísmos -una tasa menor que en el resto de grupos-y menos del $6 \%$ de elisiones de objeto -tasa similar a la de los otros grupos-, frente a $84.3 \%$ de formas emergentes, como se mostraba en la tabla 2) y algo mayor en el caso de las formas emergentes sin distinción de número $(58.5 \%$ de lo con referente plural versus $9.8 \%$ de elisiones y $31.6 \%$ de formas plurales, como se mostraba en la tabla 5).

Por ello, analizamos en el grupo con mayor variación de formas pronominales cuáles eran las entidades más adecuadas para ser candidatos gramatical y discursivamente como referentes de las formas emergentes. El resultado es que son los objetos más prototípicos -sintagmas nominales definidos, no humanos, inanimados y continuos (en el caso de las formas emergentes sin especificación de género)- los que favorecen el 
cambio. Parece, igualmente, que los contextos de mayor accesibilidad y continuidad referencial que implican la máxima activación del referente-aquellos en los que el referente está activo en la memoria del hablante, bien porque se menciona en una frase anterior, bien porque es tópico de discurso- favorecen igualmente las formas emergentes. Es esta accesibilidad la que permite que estas entidades sean referidas mediante formas menos complejas en términos de especificación de género y número, más gramaticalizadas; de esta manera el oyente puede acceder a estas entidades sin que la referencia se pierda. Esta concordancia de objeto tendrá la función de anticipar en el verbo que el objeto es importante, es decir, que está ligado fuertemente al evento.

Estos resultados parecen apoyar nuestra hipótesis inicial de que estas formas sin especificación de los rasgos de género o número del referente muestran un alto grado de gramaticalización, esto es, tienden a convertirse en formas de concordancia de objeto, alcanzando este estatus en el grupo de los bilingües consecutivos de español.

Esta perspectiva de análisis coincide con la de diversos trabajos que defienden que en ciertas variedades de español, entre las que se encuentra la mexicana (Company 2001, Belloro 2012, García-Miguel 1991, Gómez Seibane 2012, Torres Cacoullos y Esteban Hernández 1999, Vivanco 2013, Girón Alconchel 2002, entre otros), las formas pronominales manifiestan propiedades que las acerca a la concordancia de objeto, sobre todo en el dativo pero también en el acusativo aunque en menor grado, ya que pueden tener una referencia débil, pueden referir a entidades indefinidas e inespecíficas, pueden duplicarse tanto si los referentes son animados o inanimados, o pueden perder los rasgos morfológicos de género o número típicos de las formas pronominales, entre otros. En nuestro estudio, como hemos mostrado, el cambio en las formas de acusativo está muy desarrollado.

Los mismos estudios señalan los contextos de duplicación como prototípicos para la gramaticalización de las formas pronominales. En este sentido, es preciso notar que en el grupo de los bilingües consecutivos de español las formas emergentes sin especificación de género o número son categóricas en esos mismos contextos, como se mostraba en las tablas 14 y 19: todos ellos se marcan mediante lo en exclusiva. Consideramos, por ello, que en los contextos de duplicación, especialmente favorecedores para la gramaticalización de las formas pronominales como concordancia 
de objeto, el proceso se ha cumplido, no así en otros contextos, donde el cambio aún no se ha completado.

Este cambio se ha observado en diferentes variedades de español en la actualidad, pero también ha sido estudiado en distintas etapas de la historia del español tanto para el objeto indirecto como para el directo (Enrique Arias 2002, Girón Alconchel 2002, Huerta 2005, Vivanco 2013); se trata, por tanto, de un cambio interno, un lento proceso de gramaticalización que tiene lugar a lo largo de la historia del español y que aún no ha concluido. Si esto es así, ¿tiene la lengua maya alguna relevancia o implicación en la reorganización de los sistemas pronominales de la zona en estudio?

Nuestra hipótesis es que es la influencia de la lengua maya la que acelera el cambio y desencadena la reorganización del sistema, y que esta tiene lugar en dos etapas sucesivas, a tenor de las tasas de uso de las formas emergentes empleadas en el corpus: un primer cambio que afecta la pérdida o neutralización de los rasgos de género y un cambio posterior, menos extendido aún, que implica a los rasgos de número de las formas pronominales.

En cuanto al primer cambio, este se realiza en congruencia con las características de la lengua maya, como vimos en la sección "El maya yucateco", que no gramaticaliza el género morfológicamente. Los hablantes bilingües perciben que las formas pronominales de objeto indirecto tampoco tienen especificación de género, de manera similar a lo que ocurre en su lengua materna, lo que pueden considerar, consciente o inconscientemente como rasgos similares a los de su lengua nativa; a partir de estas semejanzas pueden hacer converger ambas lenguas en el punto estructural donde ambas son congruentes (Palacios y Pfänder 2014). Esto supone que categorizan las formas pronominales de objeto directo como marcadas y las aproximan a las no marcadas, las de objeto indirecto sin especificación de género, extendiendo el patrón del dativo sobre el acusativo. Así, las formas de acusativo lo/s son copias de las formas de dativo le/s. Esta solución es ciertamente innovadora ${ }^{14}$, ya que, en los procesos de cambio lingüístico que afectan al sistema pronominal átono descritos en variedades de español

\footnotetext{
${ }^{14}$ Los sistemas pronominales átonos de las variedades de español en contacto con tzutujil en Guatemala (García Tesoro 2010), tepehuano en México (Torres en prensa) o quechua en Perú (García Tesoro 2013) y Ecuador (Palacios 2006) comparten las mismas soluciones innovadoras.
} 
de España o en otras lenguas románicas, se documenta que el caso que prevalece es precisamente el no marcado, el acusativo, de ahí las soluciones laístas y leístas de las variedades centrales y norteñas de España del tipo la doy un regalo a María $a_{i} / e_{i}$ doy un regalo a Juan , como muestra Fernández-Ordóñez (2001). Esta autora demuestra con una sólida argumentación que estos cambios siguen las tendencias universales de cambio lingüístico, ya que los procesos de cambio analógico parece que están orientados a favor de las formas no marcadas -la $5^{\text {a }}$ ley de Kurylowic y el $4^{\circ}$ principio del cambio analógico de Elvira-. Sin embargo, en el sistema pronominal átono de la variedad de español en contacto con el maya se ha producido un cambio analógico que parece ir en contra de las tendencias universales de cambio lingüístico que se aprecian en el caso de los sistemas españoles, ya que las formas de acusativo, el caso no marcado, copian la morfología del caso marcado, el dativo, sin diferenciación de género; esto es, el dativo es el que se impone al acusativo, que pierde la distinción de género, dando como resultado las formas emergentes lo/s tanto para referentes masculinos como femeninos. La prevalencia de $l o / s$ en estas formas emergentes, por el contrario, sí sigue las tendencias universales del cambio analógico, ya que son las formas del género no marcado, el masculino, las que prevalecen en detrimento de las formas femeninas. ¿A qué se debe, entonces, que en este sistema pronominal átono se pierda la distinción de género y se mantenga el caso?

Para explicar los cambios que los sistemas pronominales átonos de tercera persona han experimentado en España, Fernández-Ordóñez (2001) apela a los universales 32, 36 y 39 de Greenberg (1963) para mostrar la jerarquía de los afijos morfológicos nominales y su grado de cohesión con respecto al núcleo:

$$
\text { Número }>\text { Género }>\text { (Dis) continuidad }>\text { Caso }
$$

Palacios (2011) retoma la argumentación de Mairal y Gil (2004), que enuncian la Primera Ley de Behael -que alude a la cercanía icónica de los constituyentes que forman una unidad semántica y conceptual con sus núcleos-, el Principio de la Distancia de Haiman (1985) -que relaciona la proximidad lingüística con la distancia conceptual- o el Principio de Orientación Centrípeta de Dik (1997), para apoyar esta jerarquía interlingüística. Según esta argumentación, se espera que el caso se neutralice antes que el género y el número, por su posición más externa al núcleo, como ocurre en 
los sistemas pronominales referenciales de España. Sin embargo, como hemos constatado, el caso se mantiene y lo que se pierde es la morfología de género primero y de número después, lo que parece ir en contra de las jerarquías universales propuestas $\mathrm{y}$, por tanto, de las tendencias generales de cambio lingüístico. Y esta ruptura con la evolución esperable en los sistemas pronominales átonos se debe precisamente a la influencia, como hemos apuntado ya, de la lengua maya. Dado que esta no gramaticaliza el género, es este rasgo más nuclear y no el caso, más externo con respecto al núcleo, el que se neutraliza, en un proceso de cambio que hace converger ambas lenguas en ese punto de su estructura. Esto permite explicar por qué en las formas emergentes de los sistemas pronominales mexicanos en contacto con el maya prevalece la distinción de caso y no la especificación de género o número. Estamos, pues, ante un cambio lingüístico que obedece tanto a razones internas -la gramaticalización de los sistemas pronominales átonos de tercera persona en españolcomo a factores externos - la influencia de la lengua maya-; y es la lengua de contacto la que acelera la gramaticalización de las formas pronominales en concordancias de objeto e impone la dirección del cambio.

Esta conjunción de factores posibilita, por tanto, soluciones más innovadoras, congruentes con las características de la lengua maya, y desarrolladas a mayor velocidad que las que surgen en los procesos de gramaticalización motivados internamente.

En cuanto a la neutralización de la especificación de número en las formas pronominales, consideramos que se trata de un segundo cambio, menos avanzado, surgido en el ámbito de la reorganización del sistema que está teniendo lugar y desencadenado por ese primer cambio, la neutralización de los rasgos de género, que sirve como disparador. Dado que lo se convierte en una concordancia de objeto, esta sirve tanto marcar el objeto independientemente de si refiere a entidades femeninas o masculinas, plurales o singulares.

En este sentido, nuestro análisis estadístico parece justificar esta asunción, ya que es en el GII donde únicamente las variables lingüísticas son significativas estadísticamente, lo que supone que las formas emergentes aún son seleccionadas en este grupo en función de las variables lingüísticas independientes. Este segundo cambio respeta la jerarquía de 
los afijos morfológicos nominales, mencionada arriba, y su grado de cohesión con respecto al núcleo, ya que la marcación del número es más interna, más cohesionada con el núcleo, que la del género, lo que explica que se trate de un segundo proceso con una evolución más lenta. Se trata, igualmente, de un cambio analógico, donde la forma marcada del plural copia la forma no marcada del singular; el resultado es la extensión de lo a referentes tanto singulares como plurales.

Para finalizar, es preciso recordar que la lengua maya tiene marcas de objeto en el verbo, si bien en la tercera persona esta marca es fonéticamente nula (véase sección "El maya yucateco"). Esta característica abunda en las similitudes que los hablantes bilingües pueden encontrar entre el sistema pronominal átono del español y las propias características de la lengua maya, semejanzas que no solo facilitarían el cambio sino que actuarían como un acelerador del proceso, convirtiendo las formas pronominales en verdaderas concordancias de objeto sin especificación de género o número en el GII primero los contextos de duplicación, reivindicados como prototípicos para la concordancia de objeto en español, serían los que habrían consolidado estas formas de forma categórica en el GII, y posteriormente extendiendo estas nuevas formas al resto de los grupos.

\section{A modo de conclusión}

Como hemos mostrado a lo largo de estas páginas, en la variedad de español en contacto con maya yucateco se está produciendo la reorganización y recategorización del sistema pronominal átono. En esta variedad de español en contacto con maya confluyen distintos factores que nos permiten explicar la variación y el cambio que está teniendo lugar en esta variedad y que pueden resumirse en lo siguiente: al proceso de gramaticalización de las formas pronominales como concordancias de objeto que se desarrolla desde el español antiguo se unen las características de la lengua de contacto, el maya, que actúa como un acelerador del cambio y que posibilita la reorganización y recategorización del sistema pronominal átono de tercera persona, prácticamente completada en el grupo de los bilingües consecutivos de español como L2. Y es a partir de este grupo por donde el cambio se va expandiendo paulatinamente al resto de los grupos, precisamente en las entidades más prototípicas de objeto (definidas, inanimadas y continuas) en contextos de alta accesibilidad, donde el referente está más activo en la mente del hablante y del 
oyente. Así, consideramos que la atenuación morfológica de las formas pronominales está lejos de ser una simplificación del paradigma; es posible que, por el contrario, la simplificación morfológica que hemos constatado implique, paradójicamente, una complejidad lingüística relacionada con la gramaticalización de formas de concordancias de objeto. No se trata, por tanto, de simplificación sino de recategorización del sistema; y, como hemos visto, la lengua maya tiene un papel esencial en este proceso.

\section{Bibliografía}

Álvarez Murillo, E. (2008). Estudio de actitudes lingüísticas maya-español a través del análisis del discurso en Holcá, Yucatán. Tesis de maestría. México: UNAMFFyL.

Ariel, M. (1990). Accessing noun phrase antecedents. London: Routledge.

Becerra Bascuñán, S. (2007). Estudio diacrónico y sincrónico del objeto indirecto en el español peninsular y de América [E-book]. Museum Tusculanum Press, University of Copenhagen.

Belloro, V. (2008). Doblado de objeto y accesibilidad referencial. Actas del XV Congreso de la Asociación de Lingüística y Filología de América Latina. Montevideo, Universidad de la República.

Belloro, V. (2012). Pronombres clíticos, dislocaciones y doblados en tres dialectos del español. NRFH, LX. 2, 391-424.

Bogard, S. (1992). El estatus del clítico de complemento indirecto en español. R. Barriga y J. García Fajardo (eds.), Reflexiones lingüísticas y literarias. México: El Colegio de México, 171-186.

Canché Teh, F. (2014). Actitudes y aprendizaje del maya en la UIMQROO. Tesis doctoral. Barcelona: Universidad de Barcelona.

Company, C. (2001). Multiple dative-marking grammaticalization: Spanish as a special kind of primary object language. Studies in Language 25, 1-47.

De Mello, G. (1992). Se los for se lo in the spoken cultured Spanish of eleven cities. HJ, $13,165-179$. 
Dik, S.C. (1997). The theory of Functional Grammar. Part I: The structure of the clause. Berlin: Mouton de Gruyter.

Durán Caballero, J.E. y Sauma Castillo. J.E. (2003). Actitudes hacia la enseñanza de la lengua maya en el municipio de Mérida, Yucatán: Un estudio desde la perspectiva de la sociología del lenguaje. Tesis de Licenciatura. Mérida: UADY.

Enrique Arias, A. (2002). Spanish object agreement markers and the typology of object agreement morphology. S. Dworkin / D. Wanner (eds.), New approaches to Old Spanish Issues in Romance Historical Linguistics. Philadelphia: John Benjamins, 149-164.

Fernández Soriano, O. (1999). El pronombre personal. Formas y distribuciones. Bosque y V. Demonte (eds.), Gramática descriptiva de la lengua española. Volumen I. Madrid: Espasa Calpe, 1208-1273.

Fernández-Ordóñez, I. (2001). Hacia una dialectología histórica. Reflexiones sobre la historia del leísmo, el laísmo y el loísmo. Boletín de la Real Academia Española LXXXI, 389-464.

Fernández-Ordóñez, I. (2006). Del Cantábrico a Toledo: El "neutro de materia" hispánico en un contexto románico y tipológico (primera parte). Revista de Historia de la Lengua Española, 1, 67-118.

Fernández-Ordóñez, I. (2007). Del Cantábrico a Toledo: El "neutro de materia" hispánico en un contexto románico y tipológico (segunda parte). Revista de Historia de la Lengua Española, 2, 29-81.

García Tesoro, A.I. (2010). Español en contacto con el tzutujil en Guatemala: Cambios en el sistema pronominal átono de tercera persona. Revista Internacional de Lingüística Iberoamericana VIII: 2 (15), 133-155.

García Tesoro, A.I. (2013). Reorganización del sistema pronominal del español andino hablado en Chinchero, Cuzco. Revista Andina 53. Cuzco, Centro Bartolomé de las Casas.

García-Miguel, J.M. (1991). La duplicación de complemento directo e indirecto como concordancia. Verba, 18, 375-410. 
Girón Alconchel, J.L. (2002). Procesos de gramaticalización del español clásico al moderno. $\mathrm{M}^{\mathrm{a}}$ T. Echenique Elizondo y J. Sánchez Méndez (eds.), Actas del V Congreso Internacional de Historia de la Lengua Española I. Madrid: Gredos y CAM (Caja de Ahorros del Mediterráneo), 103-121.

Givón, T. (1976). Topic, pronoun, and grammatical agreement. Subject and topic. Ch.N. Li (ed.). New York: Academic Press, 149-188.

Givón, T. (1983). Topic continuity in discourse: An introduction. T. Givón (ed.), Topic continuity in discourse: A quantitative cross-language study. Amsterdam/Philadelphia: John Benjamins, 1-41.

Gómez Seibane, S. (2012). La omisión y duplicación de objetos en el castellano del País Vasco. B. Camus Bergareche y S. Gómez Seibane (eds.), El castellano del País Vasco. Universidad del País Vasco: Bilbao, 193-214.

Greenberg, J.H. (1963). Universals of language. Cambridge, Massachussets: The Massachusetts Institute of Technology Press.

Haiman, J. ed. (1985). Natural syntax. Cambridge: University Press.

Heijmen, M. (2006). U maaya t'aanil Mayab Yucataan. Hacia una Sociedad Yucateca Intercultural a través de la Acción-desde-Abajo. Amsterdam: Universiteit van Amsterdam.

Hernández Méndez E. y Sima Lozano, E. En prensa. El español en contacto con el maya y el inglés en la península de Yucatán.

Hernández Méndez, E. En prensa. Los clíticos de dativo en el español en contacto con el maya yucateco: la ausencia de concordancia con el referente.

http://cuentame.inegi.gob.mx/monografias/informacion/qroo/default.aspx?tema=me\&e= 23

Huerta, N. (2005). Gramaticalización y concordancia objetiva en el español. Despronominalización del clítico dativo plural. Verba, 32, 165-190.

INEGI (Instituto Nacional de Estadística y Geografía). (2010). Consultado el 11 de mayo de 2014 en Intercultural a través de la Acción-desde-Abajo, Amsterdam: Universiteit van Amsterdam. 
Mairal, R. y Gil, J. (2004). Los universales lingüísticos: pasado y presente. R. Mairal y J. Gil (eds.), En torno a los universales lingüísticos. Madrid: Akal, 9-88.

Palacios, A. (2006). Cambios inducidos por contacto en el español de la sierra ecuatoriana: la simplificación de los sistemas pronominales (procesos de neutralización y elisión). Huellas del contacto, vol. Monográfico de Tópicos del Seminario, 15, Puebla (México), 197-230.

Palacios, A. (2011). Nuevas perspectivas en el estudio del cambio inducido por contacto: hacia un modelo dinámico del contacto de lenguas. Lenguas Modernas, 38 (Segundo Semestre), 17-36.

Palacios, A. y Pfänder, S. (2014). Similarity effects in language contact: Taking the speakers' perceptions of congruence seriously. J. Besters-Dilger, C. Dermarkar, S. Pfänder, A. Rabus (eds.), Congruence in Contact-Induced Language Change. Language Families, Typological Resemblance, and Perceived Similarity. Berlin/Boston: De Gruyter, 219-238.

Pfeiler, B. (1993). La lealtad lingüística del indígena Maya Yucateco. Validación de la prueba de "matched-guise". Estudios de Lingüística Aplicada, 17, 82-93.

Pfeiler, B. (1999). La situación sociolingüística en Yucatán. Obtenido el 22 de septiembre de 2008, de la página web del Centro de investigaciones regionales de la Universidad Autónoma de Yucatán en http://www.mayas.uady.mx/articulos/situacion.html

Sánchez Arroba, M.E. (2009). Migración y pérdida de la lengua maya en Quintana Roo. Migración y políticas públicas. Ciudad de México: S. Vargas (Ed.) Cámara de Diputados, Universidad de Quintana Roo y Miguel Ángel Porrúa, 397-468.

Sima Lozano, E. (2011). Actitudes de monolingües de español hacia la maya y sus hablantes en Mérida. Ketzalcalli, 2, 61-80.

Sima Lozano, E. (2012). Actitudes hacia la lengua maya de un sector de población de la ciudad de Mérida. Tesis doctoral. México: Universidad Autónoma de México.

Sima Lozano, E., Perales Escudero M. y Be Ramírez, P. (2014). Actitudes de yucatecos bilingües de maya y español y sus hablantes en Mérida, Yucatán. Estudios de Cultura Maya, 43, 157-179. 
Sorenson, T. (2013). El uso del pronombre le por les en el español formal escrito según revelan los periódicos de once ciudades. Bulletin of Spanish Studies: Hispanic Studies and Researches on Spain, Portugal and Latin America, 90.2, 131-156.

Soto, G., Sadowsky, S. y Martínez, R. (2014). El le invariable en el español escrito de Chile. Literatura y Lingüística, 29, 225-248.

Thomason, S. (2014). Contact-induced language change and typological congruence. J. Besters-Dilger, C. Dermarkar, S. Pfänder, A. Rabus (eds.), Congruence in Contact-Induced Language Change. Language Families, Typological Resemblance, and Perceived Similarity. Berlin/Boston: De Gruyter, 201-218.

Torres, N. (en prensa). Simplificación del sistema pronominal átono del español de bilingües tepehuano del sureste y español. Estudios de variación geolingüística. L. Orozco, y A. Guerrero Galván (eds.). México, Instituto Nacional de Antropología en Historia.

Vivanco, M. (2103). La noción de tópico en la duplicación clítica. Dicenda. Cuadernos de Filología Hispánica, 31, 229-249.

Yoshida, S. (2013). Guía gramatical de la lengua maya yucateca para los hispanohablantes. Miyagi: Tohoku University.

Yoshida, S. (2014). Versión corregida. Guía gramatical de la lengua maya yucateca para los hispanohablantes. Miyagi: Tohoku University.

Recibido: 1 de febrero de 2015

Aceptado: 4 de febrero de 2015

Publicado: 28 de febrero de 2015 